
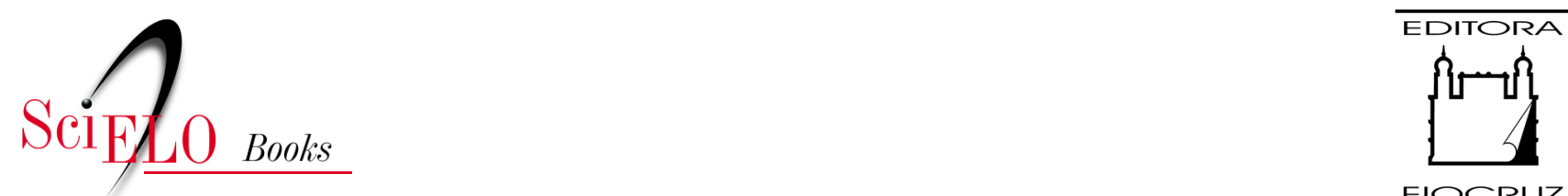

FIOCRUZ

\title{
6. Mudanças recentes no setor privado de serviços de saúde no Brasil internacionalização e financeirização
}

\author{
Célio Hiratuka \\ Marco Antonio Martins da Rocha \\ Fernando Sarti
}

\section{SciELO Books / SciELO Livros / SciELO Libros}

HIRATUKA, C., ROCHA, M.A.M., and SARTI, F. Mudanças recentes no setor privado de serviços de saúde no Brasil: internacionalização e financeirização. In: GADELHA, P., NORONHA, J.C., DAIN, S., and PEREIRA, T.R., eds. Brasil Saúde Amanhã: população, economia e gestão [online]. Rio de Janeiro: Editora FIOCRUZ, 2016, pp. 189-220. ISBN: 978-65-5708-093-1. https://doi.org/10.7476/9786557080931.0008.

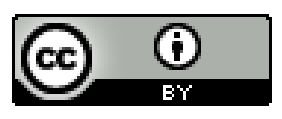

All the contents of this work, except where otherwise noted, is licensed under a Creative Commons Attribution 4.0 International license.

Todo o conteúdo deste trabalho, exceto quando houver ressalva, é publicado sob a licença Creative Commons Atribição 4.0.

Todo el contenido de esta obra, excepto donde se indique lo contrario, está bajo licencia de la licencia $\underline{\text { Creative }}$ Commons Reconocimento 4.0. 


\title{
MUDANÇAS RECENTES NO SETOR PRIVADO DE SERVIÇOS DE SAÚDE NO BRASIL: INTERNACIONALIZAÇÃO E FINANCEIRIZAÇÃO
}

\author{
Célio Hiratuka \\ Marco Antonio Martins da Rocha \\ Fernando Sarti
}

\begin{abstract}
O setor de serviços de saúde tem passado por mudanças profundas no cenário mundial, assim como no Brasil. No contexto internacional, as estratégias dos grandes grupos empresariais do setor têm sido marcadas por fusões e aquisições crescentes, de modo a ganhar escala e enfrentar os custos decorrentes das mudanças regulatórias e da incorporação de equipamentos e tecnologias mais avançados. Em grande medida, os processos de capitalização realizada por fundos de private equity têm tido um papel relevante no financiamento do crescimento, participando ativamente de fusões e aquisições promovidas por esses grandes grupos.
\end{abstract}

Esse movimento tem transbordado para a economia brasileira, que vem passando também por uma intensificação no processo de fusões e aquisições, com crescente participação de atores internacionais. Da mesma maneira, a capitalização proporcionada por fundos de private equity no Brasil é uma das características mais importantes nas transformações recentes do setor. Nos próximos anos, esse processo deve continuar a ter impactos importantes sobre a abrangência e a qualidade dos serviços privados prestados, exigindo crescente atenção dos órgãos reguladores e dos formuladores de políticas públicas de saúde.

Com o objetivo de caracterizar tais transformações e permitir um melhor entendimento das transformações recentes ocorridas no setor privado de serviços de saúde no Brasil, este capítulo está estruturado em três seções. A primeira destaca o movimento geral de internacionalização da economia, resultado de um processo de maior interpenetração dos fluxos de comércio e investimento globais, porém acompanhado de movimento intenso de centralização do capital em nível mundial. Também ressalta como, depois de um início mais concentrado nas atividades industriais, a internacionalização vem atingindo crescentemente o setor de serviços. A segunda seção, além de traçar um perfil das maiores empresas globais do setor, concentra o foco no cenário internacional de serviços de saúde, detalhando os fatores que têm impulsionado o movimento de concentração no setor, assim como sua expansão internacional. A terceira seção analisa as transformações no mercado brasileiro, destacando a tendência de maior concentração no mercado, processo que tem sido impulsionado no período recente tanto pelo movimento de entrada de empresas estrangeiras, quanto pelo destacado interesse dos fundos de investimentos nesse segmento. 


\section{Caracterização da Internacionalização}

A economia mundial vem passando por um profundo processo de internacionalização nos últimos anos. Embora o aumento das transações econômicas internacionais não seja recente, a forma como ele ocorreu no chamado processo de globalização trouxe novidades importantes.

Em primeiro lugar, deve-se destacar a velocidade do processo. Observou-se um cenário onde o movimento de internacionalização se aprofundou enormemente, ao mesmo tempo que o mapa da produção, do comércio, dos investimentos, das finanças e do conhecimento tecnológico também passou por transformações relevantes.

Uma ilustração desse primeiro processo pode ser visto no Gráfico 1, em que é possível observar como, a partir da década de 1980, o aumento das exportações de bens em relação ao Produto Interno Bruto (PIB) mundial (medido no eixo esquerdo - E) passou a ser acompanhado também pela maior internacionalização dos serviços e dos investimentos diretos (eixo direito - D). No caso dos investimentos diretos estrangeiros (IDE), o fluxo registrado de entrada mundial equivalia a cerca de 0,5\% do PIB global em 1980; passou a apresentar crescimento expressivo ao longo da década e alcançou taxas de crescimento explosivas nos anos 1990, chegando a atingir 4\% em 2000. Posteriormente sofreu flutuações importantes, sentindo os impactos da crise da economia americana em 2001; recuperou-se a partir de 2003 até atingir o patamar recorde de 4,4\% em 2007 e sofreu novamente com a crise financeira global a partir de 2008.

A internacionalização começou a se verificar também nos serviços, uma área por muito tempo considerada como menos sujeita ao processo de transnacionalização. A relação entre exportações de serviços e o PIB mundial passou de cerca de 3,5\% na década de 1980 para pouco mais de 6\% em 2012.

Além da velocidade no processo de internacionalização, também se devem destacar as transformações na forma de concorrência. Na verdade, os dados apresentados no Gráfico 1 são os aspectos mais visíveis e superficiais das profundas mudanças que vêm ocorrendo na estrutura produtiva mundial, resultado da intensificação da concorrência entre as grandes empresas globais (Chesnais, 1996).

Desde a década de 1980, a gestão e a forma de operação internacional das grandes corporações vêm se transformando de maneira acentuada, consequência em grande parte das estratégias das corporações americanas, pressionadas pela competição acirrada levada a cabo por empresas da Europa Continental e do Japão. Ao mesmo tempo, a grande empresa americana encontrou-se pressionada também pelo crescente questionamento acerca da eficiência do modelo gerencial da grande corporação multidivisional diversificada. Para os críticos desse modelo, a autonomia exagerada dos gerentes para alocar os lucros acumulados havia criado corporações excessivamente diversificadas, com a implementação de projetos de investimentos que não necessariamente geravam retornos aos acionistas. Acionistas mais ativos, remunerações atreladas ao desempenho das ações e o movimento de fusões e aquisições hostis seriam as formas de disciplinar e implantar um novo modelo de gestão, mais alinhado com o interesse dos acionistas, nessas grandes corporações (Jensen, 1989). 
Gráfico 1 - Indicadores de internacionalização econômica selecionados, em \% - 1970-2012

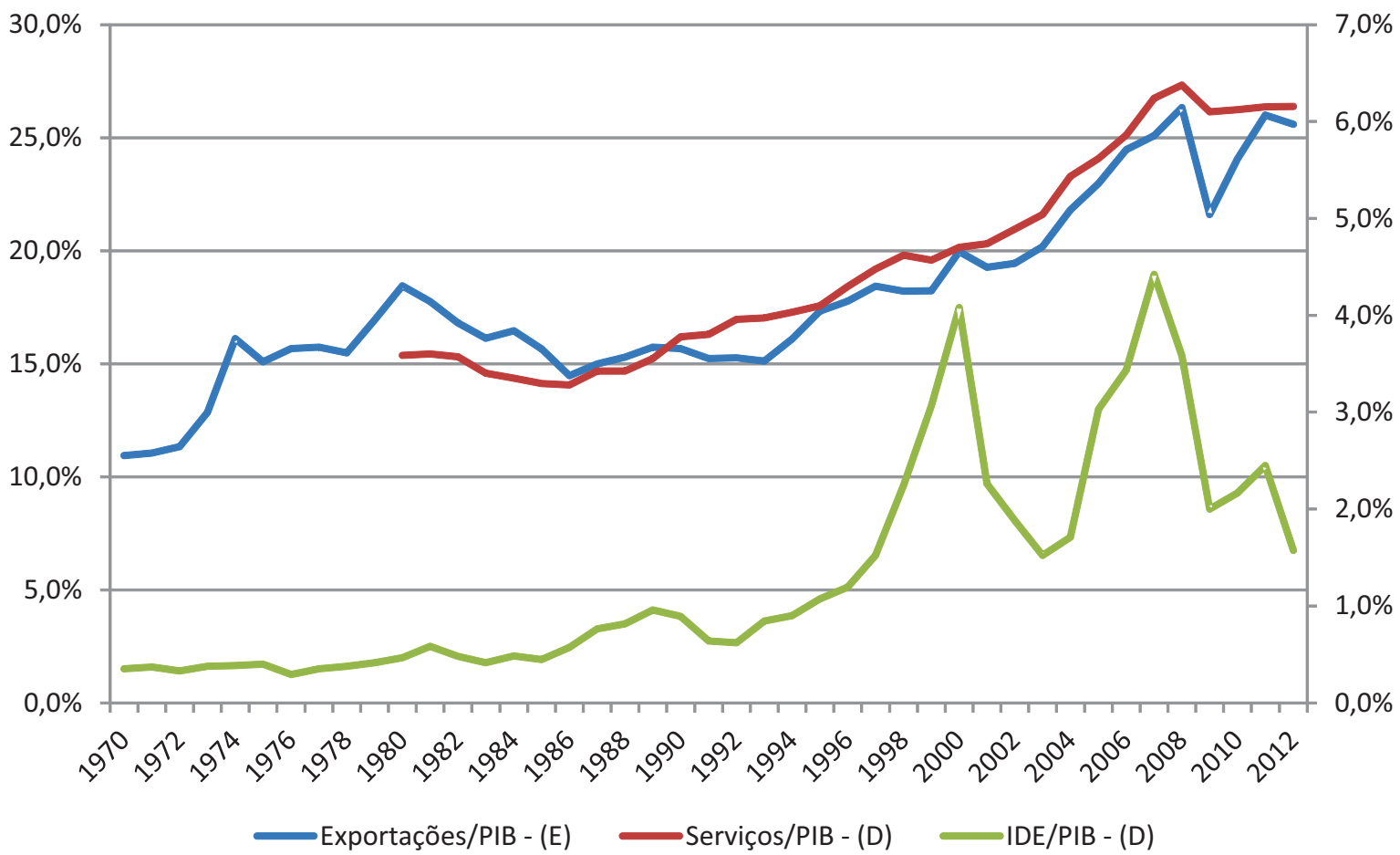

Fonte: elaboração dos autores com base em dados do World Development Indicators (WDI).

Dessa forma, as empresas americanas efetivaram ao longo dos anos 1980 um profundo processo de reestruturação, visando a associar a acumulação de ativos intangíveis com movimentos de racionalização e busca por flexibilidade, de maneira a responder ao mesmo tempo à pressão competitiva, à maior instabilidade das variáveis macroeconômicas e às exigências de retorno mais elevado e rápido, derivadas da crescente pressão do mercado financeiro sobre a gestão corporativa (Sarti \& Hiratuka, 2010).

A maior internacionalização, aliada à terceirização internacional de parcela crescente das etapas produtivas, passou a ser uma estratégia importante que resultou em uma grande descentralização das atividades produtivas. Em contrapartida, as grandes empresas buscaram reforçar seus ativos intangíveis e adquirir concorrentes estratégicos através de um processo intenso de fusões e aquisições. A elevação do poder de comando das grandes corporações dos países centrais sobre o valor gerado nas diferentes regiões foi potencializado, e o aumento do escopo global tornou-se um fator fundamental na luta competitiva, resultado das vantagens associadas à capacidade de diversificar riscos, operar em vários mercados, explorar diferenciais de custos e vantagens de localização em diferentes regiões.

Como pode ser visto no Gráfico 2, os valores das fusões e aquisições internacionais também apresentaram uma tendência clara de elevação desde os anos 1990, apesar das intensas flutuações ocorridas, seguindo o mesmo movimento observado nos fluxos de investimento estrangeiro direto (IDE). Depois de atingir um recorde de transações em 2007, quando superou o total de US\$ 1 trilhão, 
o movimento anual passou a oscilar em torno dos US $\$ 400$ bilhões anuais. A interpenetração entre os fluxos financeiros e os ativos reais também pode comprovada nesses dados, uma vez que a elevada liquidez internacional e a hipertrofia das transações financeiras resultaram em uma disponibilização ampla de recursos para alavancar a compra de ativos no mercado mundial, reforçando o processo de concentração e centralização do capital em nível global.

Gráfico 2 - Valor das fusões e aquisições internacionais (compras), em US\$ bilhões - 1990-2012

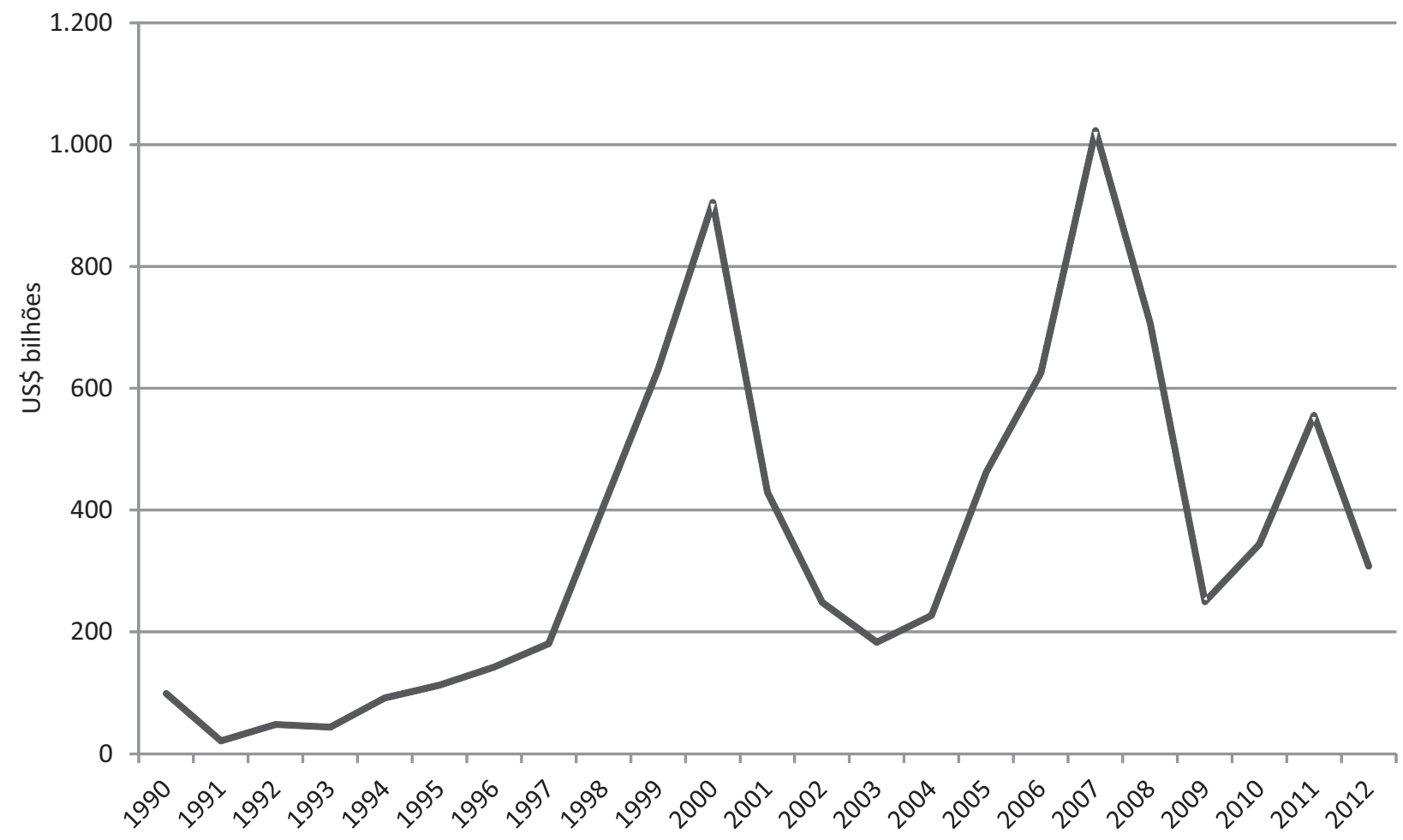

Fonte: elaboração dos autores com base em dados da United Nations Conference on Trade and Development (UNCTAD).

Separando as transações por grupo de atividade envolvida nas operações de fusões e aquisições, é possível perceber que a atividade de serviços representou grande parcela desse movimento. Mesmo não levando em consideração os serviços financeiros, que responderam na maioria dos anos pela maior parte do valor transacionado, os valores das fusões e aquisições são bastante significativos (Gráfico 3). 
Gráfico 3 - Valor das fusões e aquisições internacionais (compras) por atividade, em US\$ bilhões 1990-2012

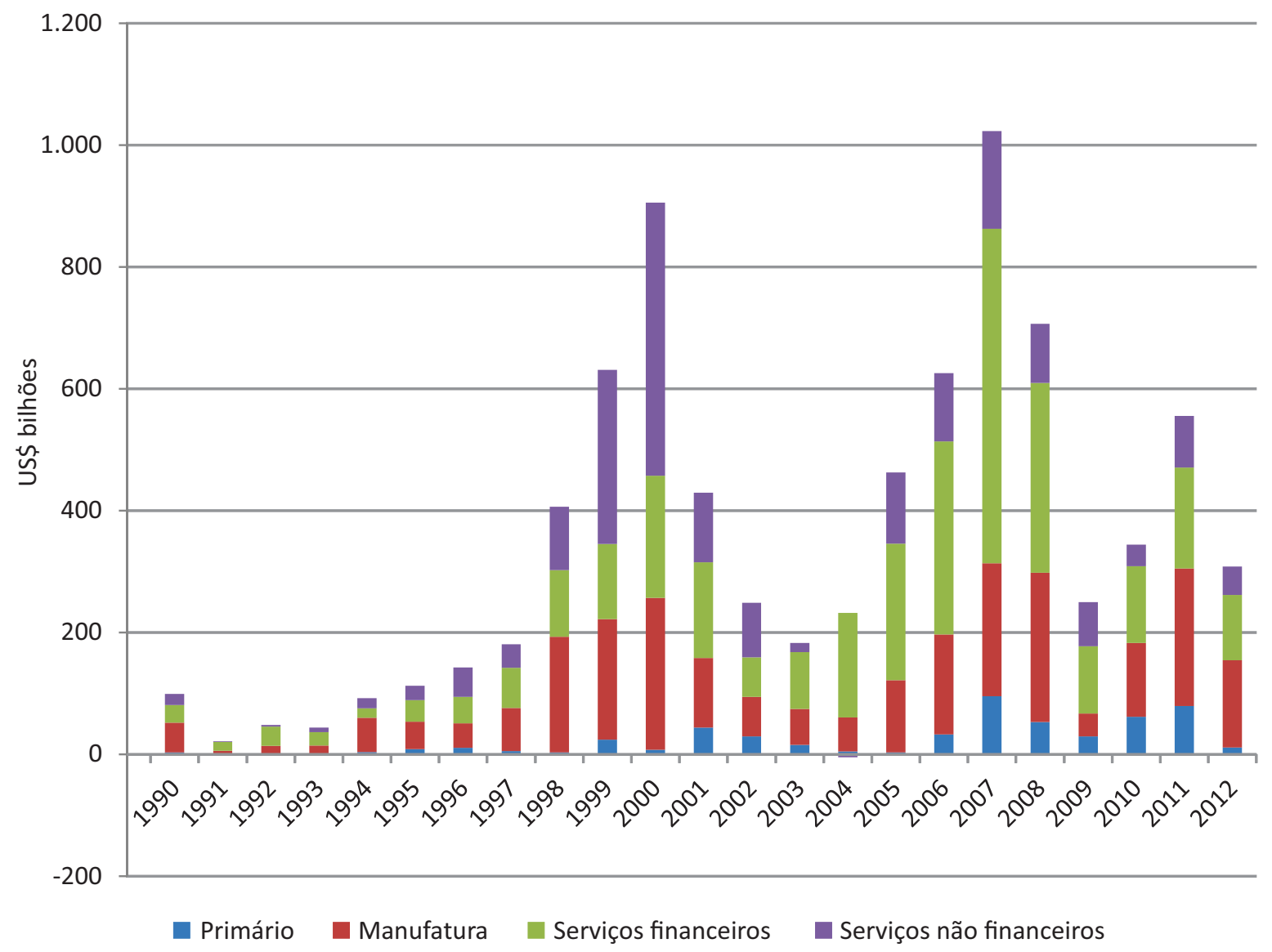

Fonte: elaboração dos autores com base em dados da UNCTAD.

Como destacado pela UNCTAD (2004), o aumento dos investimentos diretos e das fusões e aquisições no setor de serviços foi impulsionado tanto pelos processos de privatizações de setores, como telecomunicações e de energia, quanto pela liberalização ocorrida em diversos países, abrindo espaço para o capital estrangeiro em vários segmentos em que a regulamentação impedia a participação de capital externo. Também é importante ressaltar a diversificação dentro do segmento de serviços, englobando, além dos setores já citados, os de transporte, hotelaria e alimentação, e, posteriormente, atingindo setores que tinham sido menos afetados pela internacionalização, como educação e saúde.

Esses aspectos chamam atenção para a crescente internacionalização observada na economia mundial, acompanhada de um movimento intenso de reestruturação patrimonial com um processo expressivo de fusões e aquisições, resultando em um grau de centralização de capital sem precedentes em vários setores e atividades. Se, em um primeiro momento, as atividades industriais sofreram de maneira mais intensa esse processo, mais recentemente os setores de serviços têm sido afetados 
também. A princípio, os setores de energia e telecomunicações foram os vetores desse movimento, mas essa tendência tem se expandido para outros setores, mais diretamente relacionados com a oferta de serviços básicos à população e, portanto, também mais sujeitos à regulação estatal, como educação e saúde.

As análises das transformações recentes no setor de serviços de saúde no Brasil devem ter esse movimento como pano de fundo. A sua dinâmica, portanto, precisa ser entendida considerando os condicionantes colocados por essa tendência mais ampla de internacionalização mundial.

Antes, porém, de analisar especificamente as transformações no setor de serviços de saúde no Brasil, cabe realizar uma avaliação das características mais específicas das particularidades estruturais do setor, assim como uma análise mais detalhada das empresas líderes mundiais e de suas estratégias.

\section{Serviços de Saúde: caracterização internacional e empresas líderes}

\section{Caracterização geral}

Há uma série de fatores que torna a saúde, do ponto de vista da organização econômica, um setor repleto de particularidades, de difícil enquadramento nas normas convencionais de regulação dos mercados. Em outros termos, poucas características do setor de saúde justificariam deixar sua regulação à mercê meramente das leis de mercado. Esses fatores vão de uma estrutura peculiar de demanda e oferta ao relacionamento do setor com o avanço tecnológico, passando pela forma pela qual o risco e a assimetria de informação afetam a organização do setor. Esse cenário fornece ao setor, por vezes, uma dinâmica de concorrência com forte caráter concentrador, e, em se tratando de saúde, a criação de poder de mercado em relação ao consumidor é particularmente mais problemática do que o usual em outros mercados.

Dentro do macrossetor de saúde, as empresas prestadoras de serviços de saúde também se inserem nessa dinâmica. No segmento incluem-se empresas, tais como seguradoras e cooperativas de saúde, laboratórios de análises clínicas e serviços radiológicos, empresas administradoras e proprietárias de hospitais e clínicas e empresas de logística de saúde, como fornecedoras de insumos médicos e prestadoras de serviços de remoção. Compondo parte do macrossetor de saúde, esse conjunto de empresas, por um lado, compartilha algumas características gerais que definem a saúde como um setor econômico; por outro, por não estarem ligadas diretamente à produção, tais como as farmacêuticas ou as empresas de equipamentos médicos, têm uma lógica de concorrência própria pautada por alguns aspectos bem específicos ao seu conjunto de atividades.

A primeira questão de ordem geral diz respeito ao fato de o setor de saúde ser responsável pelo fornecimento de algo que é constitucionalmente reconhecido como um direito subjetivo, compondo parte dos direitos de cidadania e visando à universalidade de acesso, ao mesmo tempo que a saúde é uma mercadoria altamente geradora de valor (Conill, 2008). Ao reconhecimento desse problema deve-se, em boa parte, a organização dos sistemas nacionais de saúde, cuja organização afeta diretamente a lógica de atuação das empresas privadas. 
Destaca-se, ainda, o fato de o fornecimento de serviços de saúde ser uma atividade altamente geradora de externalidades positivas para o sistema econômico como um todo. Nesse sentido, o fornecimento de serviços em todos os níveis, e principalmente em atenção básica, contribui para a maior eficiência do funcionamento do setor, justificando a atuação da esfera pública na regulamentação e complementação da oferta de serviços.

A organização dos sistemas nacionais de saúde define em formas gerais a divisão de trabalho entre a esfera pública e a privada, assim como a estrutura de financiamento e as formas de remuneração das empresas privadas de serviços de saúde. Dessa forma, as modificações nos sistemas de saúde afetam os padrões de concorrência do setor, e este fenômeno pode ser facilmente percebido nas ondas de fusões, aquisições e mudanças nas estratégias das grandes empresas que se seguem às mudanças nas legislações que regulam os sistemas públicos de saúde. Além disso, o setor geralmente caracteriza-se também pela existência de empresas não lucrativas, como instituições religiosas e de caridade ou ligadas a grupos étnicos específicos.

No que tange à estrutura de demanda dos serviços de saúde, algumas características são particularmente importantes para compreender a relação entre usuários e empresas. Do ponto de vista do usuário, a demanda por serviços é marcada por uma forte assimetria de informação, entre ele e o especialista que os prescreve, impondo ao serviço demandado um caráter de necessidade, caracterizado pela baixa elasticidade-preço e, sobretudo, pela imprevisibilidade dessa demanda (Iunes, 1995). Dada também a incerteza a respeito da utilização e custos desses serviços, é normal a interposição de agentes administradores do risco, como seguradoras, que, por estarem geralmente associadas a uma rede específica de fornecedoras de serviços, tendem a restringir a livre substituição entre essas fornecedoras.

A visão de que o fornecimento de serviços de saúde é marcado principalmente por imperfeições de mercado, que o afasta do que seria o funcionamento adequado de um mercado segundo a teoria convencional, faz parte das contribuições do artigo seminal de Arrow (1963) sobre o tema. Segundo o autor, as imperfeições afetariam não só a estrutura de demanda como também a estrutura de oferta do setor. Primeiramente, em relação à capacidade das empresas de discriminar preço em relação às faixas de renda e realizar cobranças diferenciadas - como taxas extras vinculadas à utilização de certos serviços - que, associada a uma baixa elasticidade-preço, possibilita às empresas, como ensina qualquer manual convencional de microeconomia, uma grande capacidade de se apropriar do excedente do consumidor. Outro aspecto é a importância que a informação sobre o histórico dos pacientes e a aplicação de métodos de tratamento e diagnóstico tem na composição dos custos e na formação dos preços, o que contribui para gerar vantagens competitivas para formas mais concentradas de comando sobre a cadeia de empresas do setor, tais como empresas verticalizadas ou associações entre empresas.

No que se refere à assimilação de tecnologias por parte das empresas de serviços de saúde, embora estas não sejam geralmente produtoras de novas tecnologias, têm uma posição importante na disseminação tecnológica de novos métodos e produtos. Por concentrarem a oferta de serviços de saúde, as fornecedoras de serviços de saúde se estabelecem como interfaces entre o usuário final e as empresas inovadoras, definindo as condições de utilização e o ritmo da adoção de novas tecnologias. 
Nesse sentido, são responsáveis por boa parte do fornecimento das informações necessárias às mudanças incrementais, adaptações e ajustes para a utilização de novas tecnologias. Em muitos casos, as pesquisas são realizadas dentro das próprias empresas - como no caso dos hospitais e clínicas -, embora não tenham necessariamente a participação delas nos resultados e no financiamento. Mesmo assim, a cooperação entre os diversos elos da cadeia de fornecimento de serviços de saúde para a geração de certa estabilidade e continuidade das condições de pesquisa é fundamental para o avanço tecnológico na área.

Da perspectiva das empresas de serviços de saúde, a adoção de novas tecnologias também significa, em muitos casos, custos fixos crescentes. Dada a capacidade de discriminação de preços e de cobranças diferenciadas por serviços, o uso de novas tecnologias constitui um fator de competitividade e de aumento da rentabilidade via diferenciação da oferta, o que induz um ritmo acelerado na adoção de inovações e, simultaneamente, fortes pressões para ampliar a escala de operação. Este movimento acaba gerando um viés concentrador na disputa, sobretudo, em relação aos novos mercados.

Desse modo, a dinâmica concorrencial fica sujeita a uma tendência constante de aumento da importância das economias de escala, enquanto as mudanças na organização dos sistemas públicos de saúde podem contribuir para ampliar ou reduzir o espaço de atuação das empresas, assim como impor limites a práticas discriminatórias de preços e a certas condutas estratégicas das empresas líderes. Esses conflitos podem reduzir o mercado das empresas, levando-as à adoção de estratégias de diversificação e internacionalização mais ou menos acirradas.

Tal cenário foi particularmente o que se apresentou nos anos recentes, caracterizado por um conjunto de mudanças na organização dos sistemas públicos de saúde nos países centrais. Essas mudanças levaram as empresas a buscar a ampliação de seus espaços de atuação e suas escalas de operação, internacionalizando e verticalizando as atividades, o que provocou mais uma onda de fusões e aquisições. Contribui para a velocidade desse processo o aporte de capital proveniente de diversos fundos financeiros, que têm procurado adquirir participação em grandes empresas de serviços de saúde ou formar joint ventures para o processo de crescimento de alguma delas (Patterson, 2013).

As operações totais de fusões e aquisições realizadas globalmente apresentam uma tendência clara de aumento desde o início dos anos 2000 (Gráfico 4). O número de operações registrado foi de 39 em 1999, crescendo rapidamente a partir de então, até chegar a 415 operações em 2008. A crise internacional faz com que ocorra uma queda em 2009, porém o crescimento volta a acontecer a partir de 2010. O ano de 2012 registrou o recorde de 432 operações, seguido por pequena queda em 2013. Em termos de valor, ${ }^{1}$ a ocorrência de algumas operações com valor elevado torna a série mais volátil, com picos em 2003 e 2004, quando foram atingidos valores superiores a US\$ 30 bilhões. No entanto, mesmo com a redução posterior, o patamar das operações globais permanece entre U\$ 10 e 15 bilhões por ano.

\footnotetext{
${ }^{1}$ Nem todas as operações têm informações de valor registradas. O valor das operações corresponde apenas à soma das operações com valor registrado.
} 
Esse fenômeno tem acelerado o ritmo de concentração do mercado e contribuído para o crescimento do porte das principais empresas globais. O aumento da renda dos países em desenvolvimento, resultando no surgimento de uma ampla gama de novos consumidores, permitiu a esse processo ganhar fôlego e acirrar a corrida à aquisição de ativos estratégicos para o aproveitamento desses mercados.

Gráfico 4 - Fusões e aquisições no setor de serviços de saúde, em número de operações e valor, em US\$ bilhões - 1997-2013

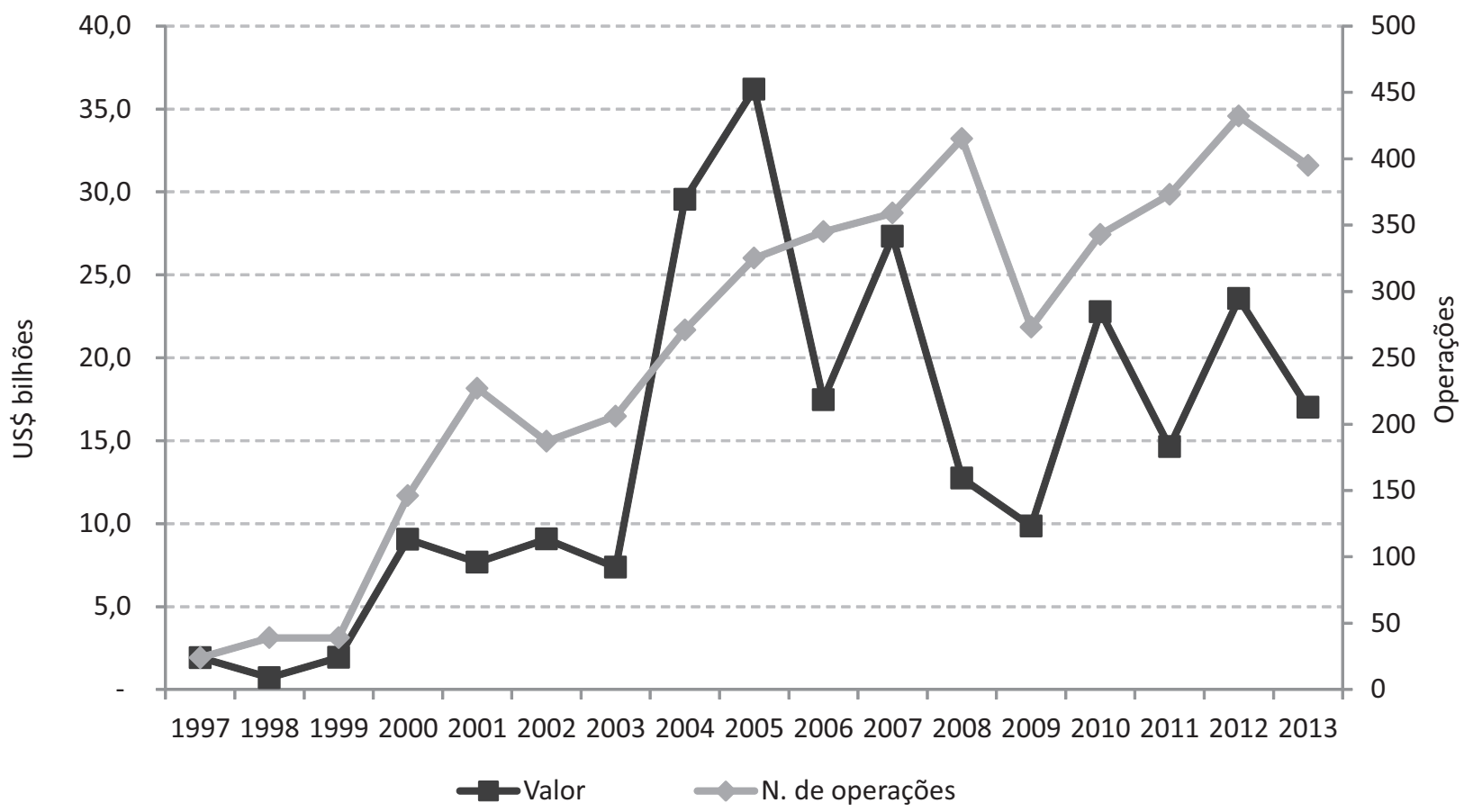

Fonte: elaboração dos autores com base em dados da Zephir-Bureau van Dijk (BvD).

Considerando apenas os processos de fusões e aquisições internacionais, isto é, quando as empresas adquirentes e adquiridas são de países diferentes, observa-se também uma elevação ao longo dos últimos anos. O número de operações foi de apenas cinco em 1997, e passou a registrar crescimento acentuado, chegando a 62 em 2008. Após a crise, observa-se uma desaceleração, porém em 2013 o número de operações atinge novo recorde, com 64 operações registradas. Em termos de valor, os patamares apresentam um crescimento consistente, especialmente a partir de 2004, quando, apesar da volatilidade, é possível perceber um volume de transações com valor mais elevado. O ano de 2012 marca o auge dos valores registrados, com US\$ 6,6 bilhões (Gráfico 5). 
Gráfico 5 - Fusões e aquisições internacionais no setor de serviços de saúde, em número de operações e valor, em US\$ bilhões - 1997-2013

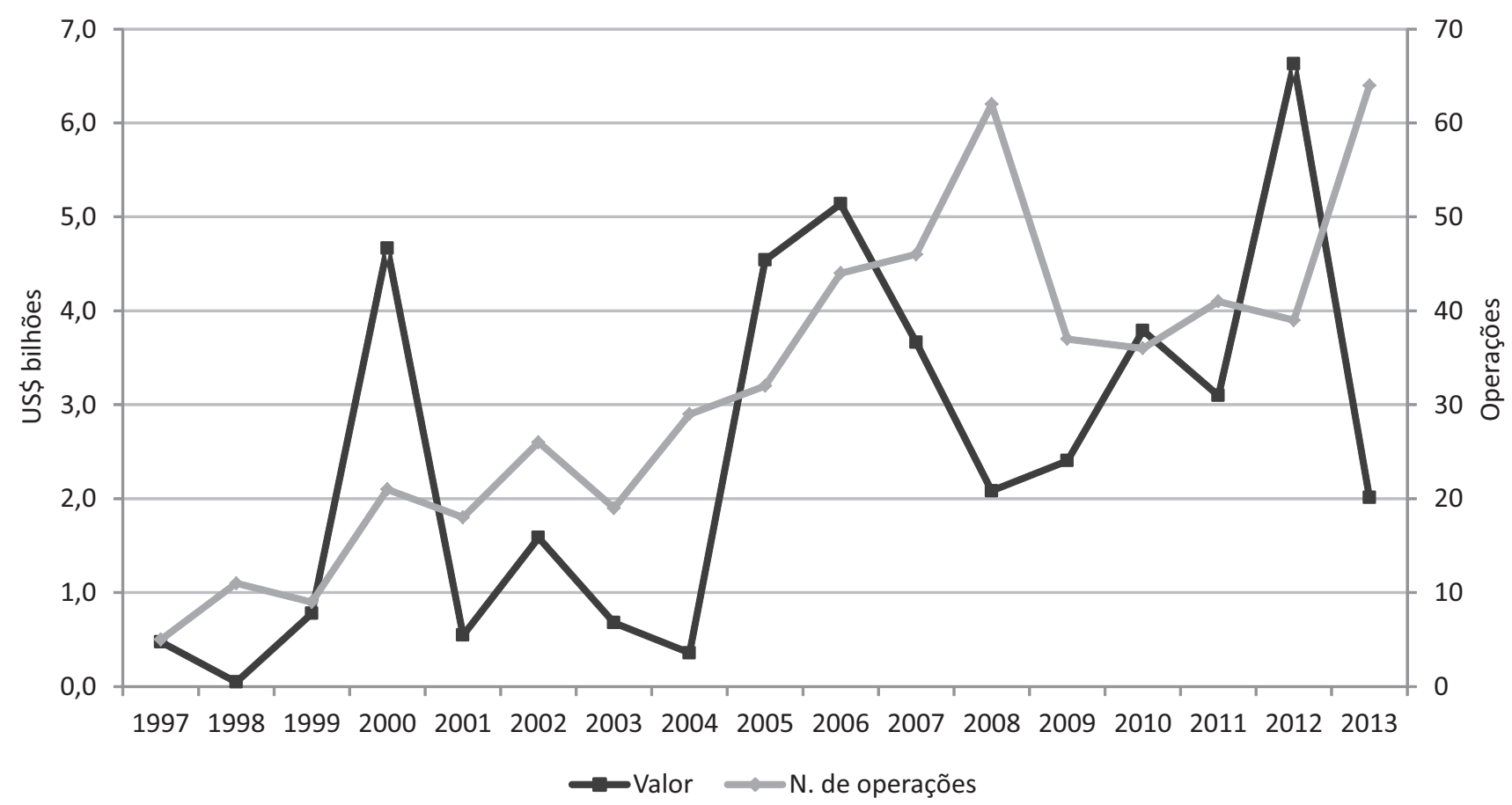

Fonte: elaboração dos autores com base em dados da Zephir-Bureau van Dijk (BvD).

O movimento de concentração iniciado nos países centrais vem se espalhando para os países em desenvolvimento, tendo como efeito o aumento da participação de empresas estrangeiras nos sistemas nacionais de saúde destes países. A seção seguinte apresenta as principais características do crescimento das maiores empresas de serviços de saúde que operam internacionalmente.

\section{Crescimento recente das empresas líderes de serviços de saúde}

O impacto da crise econômica sobre os sistemas nacionais de saúde dos países desenvolvidos se fez sentir na reorganização dos gastos sociais a partir da restrição da política fiscal a que muitos deles ficaram sujeitos. Ao mesmo tempo, a própria crise provocava o crescimento do desemprego e da pobreza, e exigia desses sistemas uma ampliação dos cuidados necessários à população com renda mais baixa. Os efeitos sobre as empresas dos países desenvolvidos foram bem assimétricos, resultando, em alguns casos, como nos Estados Unidos, em um forte movimento de concentração e internacionalização em direção a mercados em expansão. ${ }^{2}$ Esse movimento foi acompanhado do surgimento de novas sociedades entre empresas e fundos financeiros. As sociedades formadas

\footnotetext{
2 O número de fusões e aquisições na área de serviços de saúde mais do que dobrou no período pós-crise nos Estados Unidos - chegou a 105 operações somente no ano de 2012 -, criando a segunda maior onda de fusões e aquisições desde a rodada de concentrações ocorridas após a reforma de 1990 de Hillary Clinton.
} 
permitiram uma capitalização considerável, elevando em média o tamanho das empresas envolvidas na disputa internacional dos mercados de serviços de saúde.

As principais empresas de serviços de saúde selecionadas aqui - UnitedHealth, Hospital Corporation of America (HCA), Community Health Systems, Fresenius Medical Care, NetCare, Ramsay Helath Care, Kindred Healthcare, Rhön-Klinikum AG (RHK) e Capio AB - representam um grupo significativo desse processo. Ainda que a presença da família fundadora não seja incomum em algumas empresas de grande porte, a composição dos acionistas minoritários também vem se tornando característica. A formação de consórcios de fundos financeiros de grande porte tem sido o principal fator determinante da dinâmica de concentração do mercado internacional (Tabela 1).

Tabela 1 - Receita operacional e ativos totais das empresas de serviços de saúde escolhidas, em US\$ bilhões - 2012

\begin{tabular}{|l|c|c|c|}
\hline \multicolumn{1}{|c|}{ Empresa } & Origem & Receita operacional & Ativos totais \\
\hline UnitedHealth & EUA & 99,7 & 80,8 \\
\hline HCA & EUA & 18 & 63 \\
\hline Community Health & EUA & 13 & 16,6 \\
\hline Fresenius AG & Alemanha & 72 & 112 \\
\hline NetCare & África do Sul & 7,3 & 16,4 \\
\hline Ramsay Health Care & Austrália & 4 & 3,7 \\
\hline Kindred Healthcare & EUA & 4,9 & 4,2 \\
\hline RHK & Alemanha & 4 & 4,2 \\
\hline Capio AB & Suécia & 1,6 & 2 \\
\hline
\end{tabular}

Fonte: elaboração dos autores com base em dados da Zephir-Bureau van Dijk (BvD).

A UnitedHealth, a maior das empresas analisadas, é emblemática nesse sentido. Fundada em meados da década de 1970 por uma associação de médicos, abriu capital em 1984 e iniciou uma série de aquisições no começo dos anos 1990, terminando a década já como um dos principais conglomerados do setor nos Estados Unidos. Seguindo a trajetória de concentração do mercado norte-americano, a UnitedHealth iniciou nos anos 2000 mais uma rodada de aquisições, incluindo algumas grandes empresas. Ao longo da última década adquiriu a Pacificare Health Systems por cerca de US\$ 8,7 bilhões, a Oxford Health Plans por US\$ 5 bilhões, a Sierra Services por cerca de US\$ 3 bilhões e a Amil, principal ativo da companhia fora dos Estados Unidos, por aproximadamente US\$ 6 bilhões.

A participação dos fundos financeiros foi fundamental nesse processo. A UnitedHealth possui uma estrutura acionária bastante pulverizada, composta por vários fundos de investimento, dos quais o Blackrock é o principal controlador com 6,2\% das ações. O Blackrock, por sua vez, é composto por um conjunto grande de sócios, entre os quais os mais importantes são o PNC Financial, Wellington Management, Barclays, o governo da Noruega e o JP Morgan. Ao longo desse período, com o aporte 
de capital dado pelos fundos ao seu processo de crescimento, a UnitedHealth tornou-se a maior empresa do setor nos Estados Unidos e uma das maiores do mundo, com receita operacional próxima de US\$ 100 bilhões de dólares e com ativos totais de cerca de US\$ 80 bilhões em 2012.

A Hercules Holding Inc., proprietária da HCA, embora mais recente, apresenta uma história semelhante. A companhia passou a ocupar a posição de segundo maior conglomerado de saúde nos Estados Unidos, depois de um rápido processo de crescimento via fusões e aquisições financiadas por fundos de investimento. A holding foi organizada a partir de 2006 com o fechamento do capital e incorporação dos ativos da HCA pela Hercules Holding, que passou a controlar os ativos reunidos da área de serviços de saúde. É controlada atualmente por um consórcio grande de fundos de investimento, cujos principais acionistas são Bain Capital Investors e Kohlberg Kravis Roberts \& Co. (KKR), entre outros fundos sediados principalmente nos Estados Unidos e Reino Unido.

Após a incorporação da HCA pela Hercules Holding, a companhia adquiriu uma série de hospitais, clínicas e laboratórios na Austrália, Canadá, Suécia, Finlândia e Reino Unido. Esse processo foi acompanhado da reestruturação dos negócios da holding nos Estados Unidos, com a venda de um conjunto vasto de hospitais de médio porte e a concentração dos negócios em redes de grandes hospitais. A companhia também focou sua estratégia na compra de empresas de planos de saúde, sobretudo no Reino Unido. Em 2014 o fundo Bain Capital, controlador da holding, anunciou a compra do Grupo NotreDame Intermédica, sediado em São Paulo, com negócios na área de seguros de saúde, centros clínicos, hospitais e prontos-socorros.

A companhia reúne atualmente cerca de 2.400 subsidiárias, espalhadas por mais de dez países, atuando em seguros de saúde, análise clínica, assistência médico-hospitalar e logística médica. No ano de 2013, essas subsidiárias apresentaram uma receita operacional de cerca de US\$18 bilhões, com ativos totais na ordem de US $\$ 63$ bilhões, compondo um dos maiores conglomerados de serviços de saúde dos Estados Unidos. Deve-se ressaltar também que os principais controladores da holding, Bain Capital e KKR, participam do controle de outra série de empresas independentes que atuam no segmento de serviços de saúde nos Estados Unidos e em outros países.

O Community Health Systems pode ser considerado o terceiro grande conglomerado formado nos Estados Unidos a partir dos fundos financeiros. A companhia é controlada pelos fundos Glenview Capital Management, Baron Capital e Blackrock, com 10,6\%, 6,15\% e 5,6\% respectivamente, acompanhados por um vasto número de pequenos acionistas. O fundo Blackrock também consta entre os principais acionistas da UnitedHealth e da Kindred Healthcare. Em 2012, o Community Health encerrou o ano com receita operacional de US\$13 bilhões aproximadamente e um total de ativos de US\$16,6 bilhões.

O conglomerado apresentou também um crescimento recente sustentado pela atuação dos fundos de investimentos, através da capitalização de uma estratégia acirrada de compra de outras grandes empresas. Esse processo permitiu que o Community Health triplicasse de tamanho entre os anos de 2006 e 2008. A partir de 2007, a empresa adquiriu a Triad Hospitals por cerca de US\$ 7 bilhões, a Tenet Healthcare por US\$ 7,5 bilhões, e recentemente a Health Management por aproximadamente US $\$ 8$ bilhões. A rodada de compras do Community Health, somada às grandes aquisições dos outros 
três grandes conglomerados com base de operação nos Estados Unidos, fornece bem uma ideia da proporção que a concentração do mercado norte-americano vem tomando a partir da onda de fusões e aquisições da segunda metade da década de 2000.

O maior conglomerado do setor fora dos Estados Unidos, o grupo alemão Fresenius, controlador da Fresenius Medical Care, reúne ativos na área da saúde da ordem de US\$ 112 bilhões, com uma receita operacional em 2012 de aproximadamente US\$ 72 bilhões. O grupo tem como principal acionista a empresa familiar alemã Else Kroener-Fresenius, mas conta também com um grande número de pequenos acionistas, entre os quais se destacam o Skandinaviskan Enskilda Banken (SEB) e a Allianz, além de outros fundos de investimento de diferentes nacionalidades.

Seguindo a mesma lógica, o grupo iniciou nos anos 2000 uma série de aquisições de grande porte. Em 2001, a Fresenius adquiriu a Wittgensteiner Kliniken e, em 2005, o grupo adquiriu a Helios, terceira maior administradora de hospitais da Alemanha. Nesse período, a Frenesius ainda comprou a Renal Care Group, a APP Pharmaceuticals, a National Medical, a Liberty Dialysis Holding, a American Access Care Holdings e a Everest Healthcare, entre outras empresas que serviram de base para a ampliação dos negócios do conglomerado nos Estados Unidos. Nos países em desenvolvimento, o grupo expandiu sua presença na Índia - com a aquisição da Dabur Pharma e da Goa Formulations, ambas no setor de fármacos, e a Mafatlal Industries, produtora de equipamentos -, China, Taiwan, Singapura, México, Colômbia e Argentina.

O grupo também aumentou significativamente a presença em vários países europeus. De modo geral, a Frenesius aproveitou seu negócio original ligado aos tratamentos de diálise para diversificar as atividades em um conjunto vasto de negócios. Além das atividades de serviços médicos, o conglomerado verticalizou suas atividades para equipamentos médicos em geral, química fina, fármacos - incluindo de uso veterinário - e complementos nutricionais, setor em que vem demonstrando recentemente interesse na aquisição dessa divisão de negócios da Danone. A companhia ainda atua na América Latina em serviços de tecnologia da informação para a área da saúde em uma joint venture com a NetCare.

A NetCare é um conglomerado de capital sul-africano e inglês que opera majoritariamente na área de assistência médico-hospitalar, análise clínica e seguros de saúde. A receita operacional do grupo como um todo para 2012 foi de aproximadamente US\$ 7 bilhões, e os ativos totais contabilizaram cerca de US\$ 16 bilhões. A Netcare é controlada pelo fundo de investimentos Coronation Fund Managers, com atuação principalmente no continente africano, mas com uma ampla carteira de negócios que inclui participações relevantes na indústria automotiva, moda, indústria extrativa, telecomunicações e outras atividades em diversos países. O fundo, além do capital sul-africano, conta com um grupo vasto de capitais de diferentes nacionalidades, mas principalmente advindos de fundos norte-americanos e britânicos.

O conglomerado concentrou sua estratégia em aquisições no Reino Unido e África do Sul, salvo alguns casos isolados de compra de ativos nos Estados Unidos e Portugal. Entre essas aquisições, possivelmente a de maior importância foi a do General Healthcare Group, no Reino Unido, em 2006. A aquisição envolveu um consórcio de fundos de investimento, incluindo o Apax Partners, 
fundo controlador da Capio AB. A General Helthcare Group iniciou nos últimos anos um processo de recapitalização, por meio da venda de ativos não considerados estratégicos e de emissões primárias de ações. A partir da capitalização da General Healthcare, a NetCare adquiriu um conjunto de hospitais da Nuffield - outro grande grupo inglês de serviços de saúde - e vem transformando a General Healthcare na base da expansão do grupo Netcare no Reino Unido.

Outra empresa do hemisfério sul de crescimento acelerado foi a australiana Ramsay Health Care. A companhia acelerou esse processo via aquisições, iniciando a expansão a partir de 2000 , com as aquisições de quatro grandes empresas do setor na Austrália - a Affinity Health, a Australian Hospital Care, a Alpha Healthcare e a Benchmark Healthcare -, enquanto recebia o aporte de capital de alguns fundos importantes como o Barclays, do Reino Unido, e o FMR e o Fidelity International, ambos dos Estados Unidos. O grupo obteve em 2012 uma receita operacional de US $\$ 4$ bilhões aproximadamente e reunia ativos no valor de cerca de US\$ 3,6 bilhões. A importância do processo de capitalização para o crescimento da empresa fica claro quando observado o seu desempenho na última década - desde 2004 a receita operacional da companhia aumentou acima de $600 \%$, enquanto os ativos totais cresceram de US\$ 475 milhões para cerca de US\$ 3,7 bilhões no mesmo período.

Após a rodada de concentração no mercado australiano, a Ramsay Health Care expandiu seus negócios para o Reino Unido, França, Indonésia e Malásia. No Reino Unido, além da compra de algumas redes de hospitais de menor porte, a companhia adquiriu os negócios da Capio UK em 2007, subsidiária do grupo sueco Capio AB. Depois de algumas aquisições na França, em 2010 a companhia comprou 57\% do capital da Proclif, empresa que passou a reunir os ativos da Ramsay no mercado francês, passando a chamar-se Ramsay Santé. Em 2103, a Ramsay estabeleceu uma joint venture com o conglomerado malaio Sime Derby para a exploração de serviços de saúde no Sudeste Asiático - a Ramsay Sime Derby Healthcare.

A Kindred Healthcare, ao contrário das demais empresas líderes, permaneceu concentrada em sua principal área de negócios, assistência médico-hospitalar, e com a estratégia focada em seu mercado doméstico, os Estados Unidos, ao longo de toda a década. A exceção fica por conta da diversificação para a distribuição e revenda de fármacos, por meio da Kindred Pharmacies, e para a abertura de capital da Kindred Biosciences, recém-fundada empresa de fármacos para uso veterinário do grupo.

A Kindred é controlada por um conjunto de fundos de investimentos, cada um com pequena porcentagem de ações na companhia. O principal acionista é novamente o Blackrock, seguido pelo Wellington Management e pelo Dimensional Fund. Para o ano de 2012, a receita operacional alcançou a cifra de US\$ 4,9 bilhões, com o valor dos ativos totais de aproximadamente US\$ 4,2 bilhões. A companhia concentrou sua política de compra em empresas nos Estados Unidos que atuassem em seu core business, entre as quais as principais aquisições foram a RehabCare, por cerca de US\$ 1,3 bilhão, a Triumph Healthcare, por US\$ 500 milhões, e a Commonwealth Communities Holdings, por US\$ 125 milhões.

De modo geral, a Kindred focou seu crescimento na aquisição de hospitais, clínicas de reabilitação e de cuidado com idosos e em empresas de enfermagem especializada. A atuação dos fundos 
financeiros, assim como nos outros casos, serviu para impulsionar a rápida concentração desses mercados através da capitalização da estratégia de aquisição da companhia. Embora a Kindred não tenha iniciado seu processo de internacionalização, a concentração dos mercados de serviços de saúde nos Estados Unidos e o porte já assumido pela empresa após o processo de aquisição dos grupos concorrentes tornam bem provável sua internacionalização nos próximos anos, seguindo o movimento já iniciado pelos conglomerados líderes de mercado.

A RHK é a segunda maior empresa de serviços de saúde no mercado alemão. Embora tenha controle familiar, a companhia tem um alto percentual de ações em free float e a participação de alguns acionistas importantes, como o fundo JP Morgan e o grupo Fresenius, com 5\% do capital, formando uma participação acionária cruzada interessante entre duas grandes empresas concorrentes no mercado alemão. A receita operacional da RHK foi em 2012 de cerca de US\$ 4 bilhões, e os ativos totais alcançaram a cifra de US\$ 4,2 bilhões. Assim como a Kindred Health Care, a RHK concentrou seus negócios no mercado doméstico focado na construção, operação e administração hospitalar, crescendo com a aquisição de empresas na mesma área e aumentando gradualmente sua escala de operação.

Entre os anos de 2006 e 2009, a RHK iniciou um processo de aquisições, cujas principais compras foram a Amper Kliniken AG, a Wesermarsch-Klinik e o St. Petri-Hospitals. O processo de crescimento do grupo foi em grande parte financiado por um aporte de cerca de US\$ 1 bilhão, através da emissão de títulos subscritos por um consórcio de bancos liderado pelo Commerzbank AG e pelo Morgan Stanley. A capitalização do grupo permitiu elevar seu capital em torno de 50\% e garantir o aumento da participação da RHK no disputado mercado alemão. Assim como a Kindred Health Care, a RHK é uma das poucas, entre as grandes empresas, que manteve seu crescimento contido ao mercado doméstico.

A Capio AB é um conglomerado sediado na Suécia, controlado pelos fundos Apax Partners e Nordic Capitals, que possuem cerca de duzentas empresas nas áreas de finanças, empreendimentos imobiliários, tecnologia em tratamentos médicos e serviços de saúde, com atuação principalmente em assistência médico-hospitalar e planos de saúde. No ano de 2012, a receita do grupo foi de aproximadamente US\$ 1,6 bilhão de dólares, com um total de ativos de cerca de US\$ 2 bilhões. Está presente em quase toda a Europa, embora controle suas operações a partir das sedes na Suécia, Noruega, França, Alemanha e Reino Unido. A internacionalização do grupo, ainda que restrita ao continente europeu, foi bem ampla, com negócios relevantes na Espanha, Suíça, França, Dinamarca, Noruega, Alemanha, Reino Unido e Itália, para citar apenas as operações de maior porte.

Entre as empresas líderes, a Capio é a que apresenta maior grau de internacionalização, com cerca de $50 \%$ da receita gerada fora do mercado doméstico. A companhia investiu na aquisição do controle de algumas grandes empresas, como a suíça Unilabs, a UK Healthcare e a Community Hospitals - ambas no Reino Unido -, o Grupo Sanitario - na Espanha - e o Tonkin Group - na França. Posteriormente desfez-se de alguns ativos importantes, entre os quais o principal foi a venda da Capio UK para a Ramsay Health Care por cerca de US\$ 316 milhões. Entretanto, a internacionalização do grupo ainda está em fase de expansão, tanto em relação aos negócios da Capio $\mathrm{AB}$, quanto aos negócios na área de saúde do fundo Apax Partners, principal controlador do grupo. 
De modo geral, a associação entre fundos financeiros e empresas de serviços de saúde contribui para a rápida concentração e internacionalização dos mercados dos países de alta renda. No caso dos Estados Unidos, em que o mercado de saúde combina renda per capita alta com grande participação dos gastos privados - ao contrário dos países europeus com grandes sistemas públicos de saúde centralizados -, o nível de concentração alcançou patamares bastante elevados, com a formação de alguns dos maiores conglomerados do setor.

O processo também teve em comum algumas características em relação à conduta dos fundos financeiros. A entrada dos fundos coincidiu com um movimento de recompra de ações e fechamento de capital de algumas unidades intermediárias dos grandes grupos. Esse movimento resultou na composição de algumas grandes holdings de serviços de saúde comandadas por consórcios bem vastos de fundos de investimento, geralmente com participação acionária pulverizada e com participação de fundos de diferentes nacionalidades. A consolidação do processo vem reduzindo cada vez mais o número de hospitais, clínicas e laboratórios independentes das grandes redes que, por seu turno, vêm se tornando cada vez mais internacionalizadas.

Alguns grandes fundos como o Apax Partners, o Blackrock Inc., o Bain Capitals e o Cinven Group, ao longo da década aumentaram significativamente suas participações em diversos empreendimentos na área da saúde, espalhados em diversos continentes. Embora alguns sejam concentrados em grandes empresas do setor, a participação desses fundos é bem mais vasta que o volume de ativos reunidos nas empresas líderes; e, até mesmo pela sua liquidez no mercado de capitais e pelo alcance global de suas operações, eles vêm dando a tônica do processo de concentração. A concentração nos mercados centrais já atingiu um nível elevado, restando apenas algumas possíveis aquisições de grande porte.

Outra característica relevante dos mercados desenvolvidos é que a divisão de trabalho entre Estado e setor privado é bem restrita ao setor privado, dada a abrangência dos sistemas públicos de saúde, limitando assim também o número de atividades em que a diversificação é possível. A formação de um vasto mercado de renda per capita mais elevada nos países em desenvolvimento, com sistemas públicos de saúde precários ou de pouca abrangência, fornece um mercado em potencial para o crescimento da participação dos fundos financeiros, em mercados com taxas de expansão mais elevadas que os seus mercados domésticos originais.

\section{O Setor de Serviços de Saúde Privados no Brasil}

\section{Caracterização geral}

O setor brasileiro de provisão de serviços de saúde, medido com base nos dispêndios totais com hospitais (públicos e privados), clínicas, serviços médicos, medicamentos e equipamentos médicos, totalizou cerca de US\$ 240 bilhões em 2012. A taxa de crescimento entre 2008 e 2012 foi de 12,5\%, comparada com uma taxa de 4,6\% observada nos Estados Unidos e 4,8\% no Canadá (Marketline Industry Profile, 2013).

O Sistema Único de Saúde (SUS) é responsável pelo provimento geral de serviços de saúde universal. Nos últimos anos, porém, tem ocorrido uma movimentação importante no segmento de 
saúde suplementar, com alguns sinais de que o cenário de maior concorrência internacional, abordado na seção anterior, tem se verificado de maneira mais efetiva no Brasil, em especial no período pós-crise internacional. Os dados de crescimento apresentados anteriormente permitem perceber o diferencial em termos de taxa de crescimento entre o Brasil e Estados Unidos e Canadá, o que justifica esse interesse.

O intenso processo de alterações na estrutura do setor de serviços de saúde em nível mundial tem tido repercussões importantes na economia brasileira. Esta seção busca justamente detalhar o sentido geral dessas transformações, descrevendo as linhas gerais de mudanças observadas. Antes de entrar diretamente na análise das mudanças, serão apresentados alguns dados básicos sobre a estrutura do setor de serviços de saúde no Brasil.

Na introdução deste estudo, afirmou-se que a atenção estaria concentrada em especial nos setores de seguros e planos de saúde, hospitais e serviços de diagnóstico. Também nesta seção a atenção vai convergir para esses setores.

Antes, porém, é interessante ter uma visão mais geral das atividades relacionadas aos serviços de saúde no Brasil, com base nas estatísticas disponíveis. De acordo com as informações do Cadastro Central de Empresas do Instituto Brasileiro de Geografia e Estatística (IBGE), os dados por grupo de atividade da Classificação Nacional de Atividade Econômica (CNAE), versão 2.0, foram organizados basicamente em dois segmentos principais. O primeiro faz parte de uma divisão do setor financeiro e é composto pelos grupos de classificação Seguros de Saúde e Planos de Saúde. Já o segundo corresponde especificamente à divisão atividades de Atenção à Saúde Humana e todos os seus grupos.

Os dados da Tabela 2 mostram como, em geral, o número de empresas que atuam em cada grupo de atividade é bastante grande, com exceção do segmento Seguros de Saúde. Também é possível perceber que o número de empresas e organizações pertencentes à divisão de serviços de Atenção à Saúde Humana é muito maior do que à de Seguros e Planos de Saúde. Apesar disso, o setor de Seguros e Planos de Saúde possui número médio de pessoas empregadas e salário médio também maior. Essas informações indicam um grau um pouco maior de concentração econômica neste grupo, comparado com uma pulverização bastante grande no setor de serviços de Atenção à Saúde Humana. 
Tabela 2 - Dados selecionados de empresas do setor de serviços de saúde, por grupo de atividade - 2011

\begin{tabular}{|l|c|c|c|c|c|}
\hline $\begin{array}{l}\text { Grupo da classificação de } \\
\text { atividades }\end{array}$ & $\begin{array}{c}\text { Empresas } \\
\text { e outras } \\
\text { organizaçeses }\end{array}$ & $\begin{array}{c}\text { Pessoal } \\
\text { ocupado em } \\
31 / 12\end{array}$ & $\begin{array}{c}\text { N. médio } \\
\text { de pessoas } \\
\text { ocupadas em } \\
31 / 12\end{array}$ & $\begin{array}{c}\text { Salários } \\
\text { e outras } \\
\text { remunerações } \\
\text { (R\$ 1.000) }\end{array}$ & $\begin{array}{c}\text { Salários e } \\
\text { remunerações } \\
\text { médios }\end{array}$ \\
\hline R\$ 1.000)
\end{tabular}

Fonte: elaboração dos autores com base em dados do Cadastro Central de Empresas do IBGE.

Entre os serviços de atenção à saúde humana, deve-se destacar a elevada participação dos hospitais, tanto no número de pessoas ocupadas quanto nos salários e remunerações pagos (60\% e $75 \%$ respectivamente). Também é válido destacar que as organizações de atendimento hospitalar têm tamanho médio e salário médio superiores ao do conjunto do setor. Especificamente no setor de atendimento hospitalar, cabe ressaltar que, embora as organizações pertencentes diretamente ao setor público respondam por apenas $2,3 \%$ do total, elas representam mais de $26 \%$ do pessoal ocupado e $35 \%$ dos salários e remunerações. Este fato está relacionado ao grande porte dos hospitais públicos, com número médio de empregados maior do que 1,3 mil em 2011. Os hospitais sem fins lucrativos, também denominados filantrópicos respondem por 44\% do pessoal ocupado e 43\% das remunerações, embora sejam responsáveis por $15 \%$ das organizações. O setor privado, por sua vez, apresenta tamanho médio muito menor, representa a grande maioria das organizações (82\%), porém responde por $29 \%$ do pessoal ocupado e $21 \%$ das remunerações (Tabela 3). 
Tabela 3 - Dados selecionados de empresas do setor de atendimento hospitalar por natureza jurídica-2011

\begin{tabular}{|c|c|c|c|c|c|}
\hline $\begin{array}{c}\text { Grupo da classificação de } \\
\text { atividades }\end{array}$ & $\begin{array}{c}\text { Empresas } \\
\text { e outras } \\
\text { organizações }\end{array}$ & $\begin{array}{c}\text { Pessoal } \\
\text { ocupado em } \\
31 / 12\end{array}$ & $\begin{array}{c}\text { N. médio } \\
\text { de pessoas } \\
\text { ocupadas em } \\
31 / 12\end{array}$ & $\begin{array}{c}\text { Salários } \\
\text { e outras } \\
\text { remunerações } \\
(\mathrm{R} \$ 1.000)\end{array}$ & $\begin{array}{l}\text { Salário médio } \\
(\mathrm{R} \$ 1.000)\end{array}$ \\
\hline \multicolumn{6}{|l|}{ VALOR } \\
\hline $\begin{array}{l}\text { Atividades de atendimento } \\
\text { hospitalar }\end{array}$ & 10.389 & 1.181 .224 & 113,7 & $28.827 .416,8$ & 24,4 \\
\hline Administração pública & 237 & 317.053 & $1.337,8$ & $10.146 .864,4$ & 32,0 \\
\hline Entidades empresariais & 8.587 & 344.736 & 40,1 & $6.212 .104,6$ & 18,0 \\
\hline Entidades sem fins lucrativos & 1.565 & 519.435 & 331,9 & $12.468 .447,8$ & 24,0 \\
\hline \multicolumn{6}{|l|}{ Porcentagem } \\
\hline $\begin{array}{l}\text { Atividades de atendimento } \\
\text { hospitalar }\end{array}$ & 100,0 & 100,0 & 100,0 & 100,0 & 100,0 \\
\hline Administração pública & 2,3 & 26,8 & $1.176,6$ & 35,2 & 131,1 \\
\hline Entidades empresariais & 82,7 & 29,2 & 35,3 & 21,5 & 73,8 \\
\hline Entidades sem fins lucrativos & 15,1 & 44,0 & 291,9 & 43,3 & 98,4 \\
\hline
\end{tabular}

Fonte: elaboração dos autores com base em dados do Cadastro Central de Empresas do IBGE.

As atividades de atenção ambulatorial executadas por médicos e odontólogos respondem por 49\% das empresas, $13 \%$ das pessoas ocupadas e $6 \%$ dos salários do setor. Porém, trata-se de um serviço que se confunde com as atividades de clínica médica e que, na maior parte das vezes, não apresenta organização empresarial de porte, como pode ser visto pelo tamanho médio em termos de pessoas ocupadas. O mesmo se pode dizer do setor de serviços profissionais, exceto médicos e odontólogos (19\% das empresas, 5\% das pessoas ocupadas e 3\% dos salários).

Já as atividades de serviços de complementação diagnóstica, que respondem por uma parcela de $16 \%$ das empresas, têm uma representatividade um pouco maior em termos de pessoas ocupadas e de salários (11\% e 7\%). Além disso, apresentam número médio de pessoas ocupadas e salário médio um pouco superior ao dos dois segmentos anteriores.

As informações apresentadas justificam a concentração da análise, no restante deste capítulo, nos setores associados diretamente aos seguros e planos de saúde, além dos segmentos de atendimento hospitalar e serviços de diagnóstico. Como será observado ao longo desta seção, são nesses segmentos que as mudanças mais importantes foram detectadas, justamente por comporem as atividades de maior porte e organização empresarial.

Evidências que confirmam o observado no parágrafo anterior podem ser analisadas com base nos dados da Tabela 4. Nesta tabela, estão as 25 maiores empresas associadas aos serviços de saúde, listadas entre as empresas da publicação Valor 1000 (<www.valor.com.br/valor1000/2015>), que reúne informações financeiras das mil maiores empresas brasileiras. 
É possível perceber como, apesar da estrutura pulverizada em termos de número de empresas, existem alguns grandes grupos que atuam nos diferentes segmentos, com volume de faturamento bastante elevado. A Amil aparece como maior empresa do setor, com receita líquida de R\$ 10,4 bilhões em 2012. Em seguida aparecem duas empresas de Seguro Saúde (Bradesco e Sul América) e somente na quarta posição um grupo com atividade hospitalar (Rede D’Or). Em termos de diagnóstico laboratorial, a Diagnósticos da América (Dasa) é a maior empresa e aparece na oitava posição entre as 25 maiores.

Tabela 4 - Receita líquida das 25 maiores empresas do setor de serviços de saúde, em R\$ milhões - 2012

\begin{tabular}{|l|l|c|}
\hline \multicolumn{1}{|c|}{ Empresa } & Segmento & Receita líquida \\
\hline AmilPar & Plano de saúde & $10.464,00$ \\
\hline Bradesco Saúde & Seguro saúde & $7.743,80$ \\
\hline Sul América Seguro Saúde & Seguro saúde & $5.431,20$ \\
\hline Rede D’Or & Serviços médicos & $3.122,10$ \\
\hline Unimed Rio & Plano de saúde & $2.773,40$ \\
\hline Hospitais São Paulo & Serviços médicos & $2.484,60$ \\
\hline NotreDame Intermédica & Plano de saúde & $2.349,20$ \\
\hline Diagnósticos da América & Serviços médicos & $2.264,10$ \\
\hline Unimed Paulistana & Plano de saúde & $2.232,30$ \\
\hline Unimed Belo Horizonte & Plano de Saúde & $2.144,40$ \\
\hline Golden Cross & Plano de saúde & $1.874,10$ \\
\hline Central Unimed Nacional & Plano de saúde & $1.631,80$ \\
\hline Sul América Saúde & Seguro saúde & $1.536,00$ \\
\hline Hospital Albert Einstein & Serviços médicos & $1.528,90$ \\
\hline Fleury Medicina e Saúde & Serviços médicos & $1.501,80$ \\
\hline Hospital Santa Catarina & Serviços médicos & $1.322,10$ \\
\hline Hospital e Maternidade São Camilo & Serviços médicos & $1.316,50$ \\
\hline Santa Casa de São Paulo & Serviços médicos & $1.117,60$ \\
\hline Unimed Curitiba & Plano de saúde & $1.113,80$ \\
\hline Unimed Porto Alegre & Plano de saúde & $1.095,30$ \\
\hline Unimed Campinas & Plano de saúde & $1.026,20$ \\
\hline Esho & Serviços médicos & $1.020,00$ \\
\hline Porto Seguro Saúde & Seguro saúde & 957,90 \\
\hline Odontoprev & Plano de saúde & 956,80 \\
\hline Hospital Santa Marcelina & Serviços médicos & 904,40 \\
\hline & & \\
\hline & &
\end{tabular}

Fonte: elaboração dos autores com base em dados do Valor 1000. 
Consolidando as informações das 25 maiores empresas por segmento (Tabela 5), nota-se que, do total de R 59,9 bilhões de receita líquida observado em 2012, as 11 empresas de planos de saúde responderam por $46 \%$, com receita média de $\mathrm{R} \$ 2,5$ bilhões. As empresas de seguro saúde tiveram receita média ainda maior ( $\mathrm{R} \$ 3,9$ bilhões), as quatro empresas listadas responderam por $26 \%$ da receita. As empresas de serviços médicos, que agregam tanto hospitais quanto empresas de diagnóstico, foram responsáveis pelos $27 \%$ da receita restante e tiveram a menor receita média entre os três segmentos ( $\mathrm{R} \$ 1,6$ bilhão).

Tabela 5 - As 25 maiores empresas do setor de serviços de saúde, por segmento, em R\$ milhões - 2012

\begin{tabular}{|l|c|c|c|}
\hline Segmento & N. de empresas & Receita líquida & Receita média \\
\hline Planos de saúde & 11 & $27.661,3$ & $2.514,7$ \\
\hline Seguros saúde & 4 & $15.668,9$ & $3.917,2$ \\
\hline Serviços médicos & 10 & $16.582,1$ & $1.658,2$ \\
\hline Total & 25 & $59.912,3$ & $2.396,4$ \\
\hline
\end{tabular}

Fonte: elaboração dos autores com base em dados do Valor 1000.

A seção seguinte analisa as mudanças pelas quais tem passado o setor de serviços de saúde no Brasil, resultantes em grande medida das estratégias empreendidas pelas maiores empresas do setor.

\section{Transformações recentes no mercado nacional}

As informações analisadas nesta seção procuram destacar o movimento de concentração pelo qual vem passando o setor. Esse processo teve início na década de 2000, porém tem se intensificado nos últimos anos em razão de dois movimentos simultâneos e muitas vezes interconectados. O primeiro está associado à busca dos grandes grupos internacionais por novos polos de expansão nos países em desenvolvimento, dado o forte movimento de consolidação já ocorrido nos países centrais, assim como à busca de mercados com maiores perspectivas de aumento da demanda. O segundo está relacionado ao crescente interesse dos fundos de private equity, tanto de capital nacional quanto estrangeiro, por oportunidades de investimento no mercado de serviços de saúde no Brasil.

Com base nas informações organizadas pela Agência Nacional de Saúde (ANS), é possível ter uma ideia mais clara do movimento de concentração no setor de seguros e planos de saúde. Em termos de número de operadores, pode-se perceber, no Gráfico 6, como a tendência desde 2011 tem sido de redução. Considerando os planos de saúde, o número diminuiu de 1.456 no final de 2001 para 929 em setembro de 2013 (redução de 36\%). Para os planos exclusivamente odontológicos, a redução foi de 505 para 345 no mesmo período (31\%). 
Gráfico 6 - Número de operadores de planos de saúde com beneficiários - dezembro 2009setembro 2013

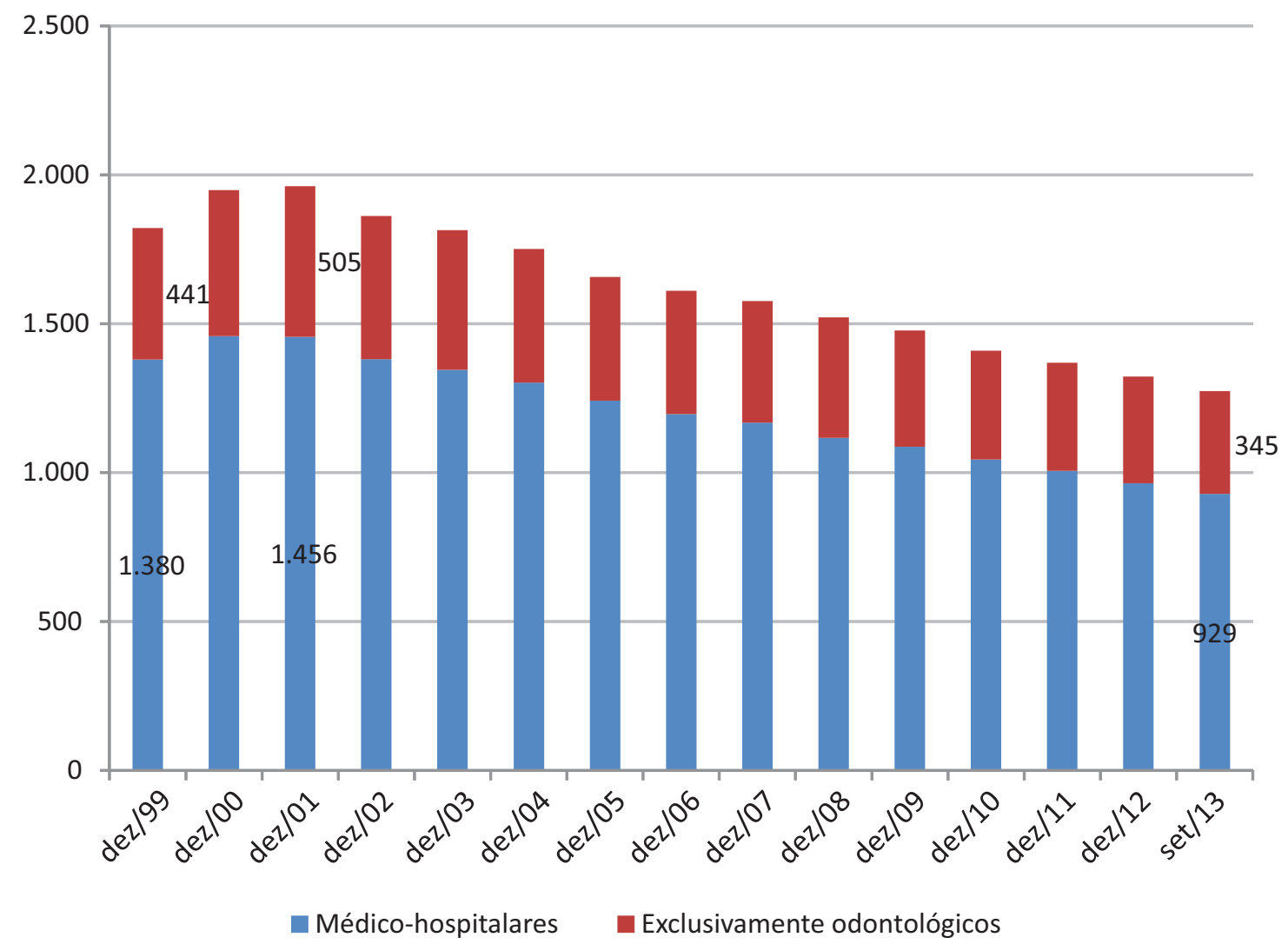

Fonte: elaboração dos autores com base em dados da ANS.

Interessante notar que a redução do número de operadores aconteceu ao mesmo tempo que o número de beneficiários passou por um aumento importante, fruto da expansão do nível de renda e do volume de emprego formal. De um total de cerca de 31 milhões de beneficiários de planos médico-hospitalares no início dos anos 2000, o total atingiu 49 milhões em setembro de 2013 (55\% de aumento). Para os planos exclusivamente odontológicos, a elevação foi ainda maior - saiu de 2,6 milhões e atingiu 19,5 milhões de beneficiários (aumento de 430\%) no mesmo período (Gráfico 7). 
Gráfico 7 - Número de beneficiários das operadoras de planos de saúde - dezembro 2000setembro 2013

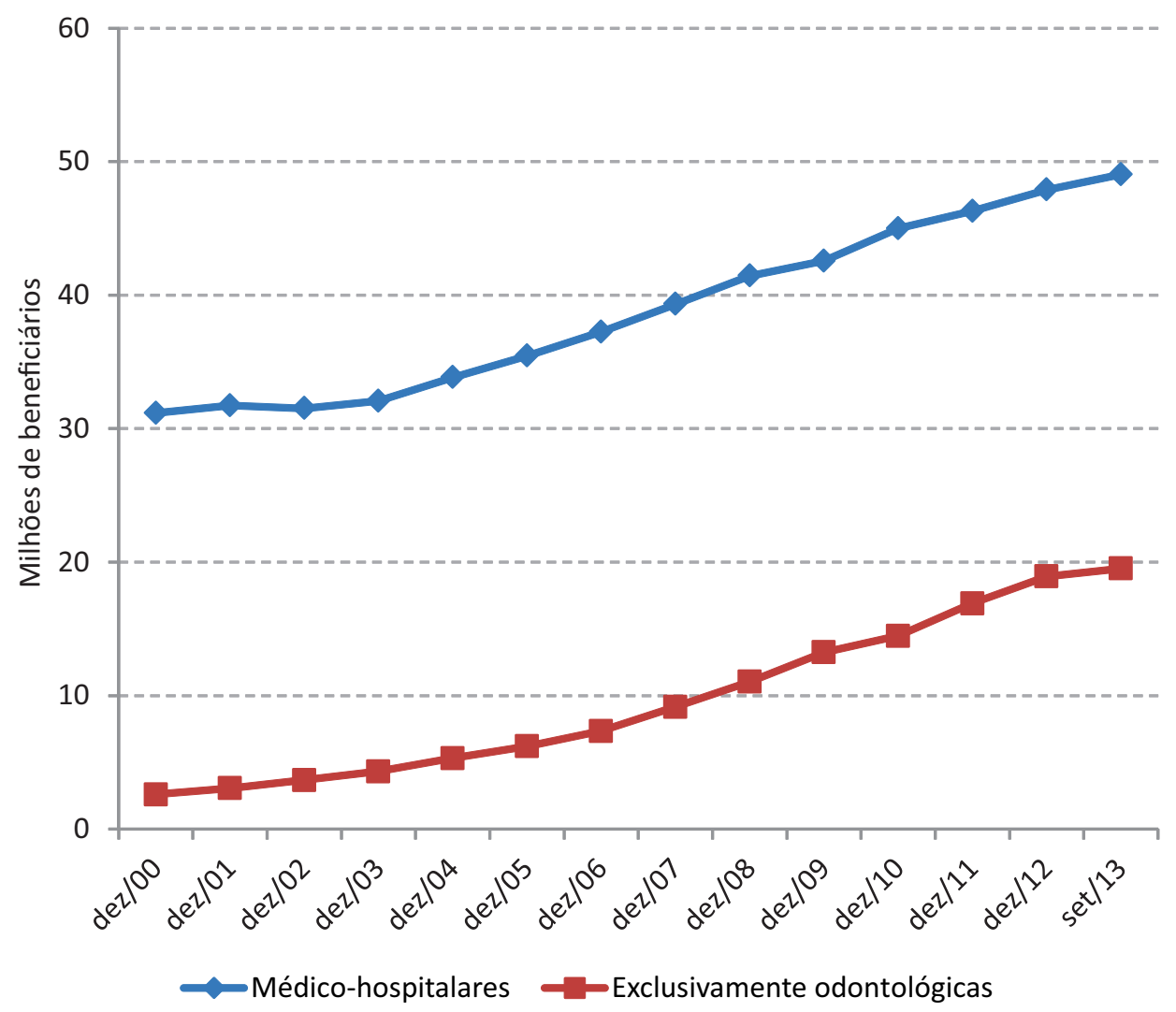

Fonte: elaboração dos autores com base em dados da ANS.

Como resultado do aumento do número de beneficiários e da redução do número de operadoras, o volume médio de beneficiários por operadora apresentou uma elevação consistente ao longo de todo o período - saiu de um patamar de 21,3 mil em 2000 para 52,7 mil em 2013. Observa-se, assim, um aumento importante nas escalas de operações do setor de planos de saúde (Gráfico 8).

Vale lembrar, porém, que, apesar do aumento da escala média, a disparidade entre os atores é bastante expressiva, pois ainda existe um número alto de empresas de pequeno porte atuando em mercados locais e regionais. Por sua vez, as grandes operadoras concentram parte importante das receitas e dos clientes. 
Gráfico 8 - Número médio de beneficiários por operadora de plano médico-hospitalar - dezembro 2000-setembro 2013

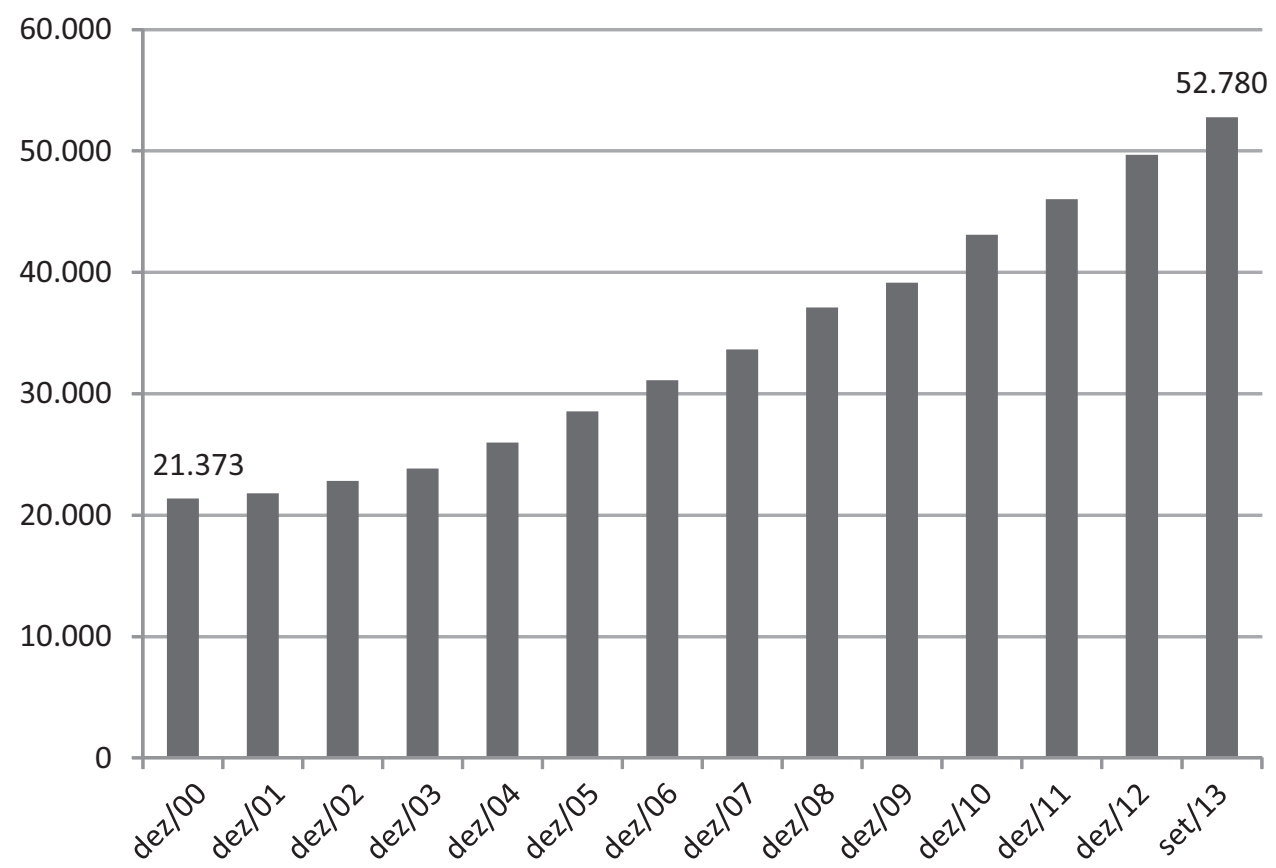

Fonte: elaboração dos autores com base em dados da ANS.

A Tabela 6 mostra como as duas maiores operadoras brasileiras atendem 14\% dos beneficiários. Caso sejam consideradas as quatro maiores, esse número chega a $21 \%$, e a $31,4 \%$ quando se consideram as oito maiores. Vinte e sete operadoras respondem por $50 \%$ dos 49 milhões de beneficiários.

Tabela 6 - Beneficiários de planos de saúde e percentual acumulado por operadora - 2012

\begin{tabular}{|c|c|c|}
\hline Número de beneficiários & Percentual acumulado de beneficiários & Operadoras \\
\hline Assistência médica com ou sem odontologia & & 2 \\
\hline 6.886 .753 & $14,0 \%$ & 4 \\
\hline 10.291 .181 & $21,0 \%$ & 8 \\
\hline 15.383 .274 & $31,4 \%$ & 15 \\
\hline 20.130 .399 & $41,1 \%$ & 27 \\
\hline 24.604 .478 & $50,2 \%$ & 51 \\
\hline 29.458 .303 & $60,1 \%$ & 95 \\
\hline 34.337 .273 & $70,0 \%$ & 168 \\
\hline 39.216 .981 & $80,0 \%$ & 306 \\
\hline 44.125 .239 & $90,0 \%$ & 926 \\
\hline 49.032 .912 & $100,0 \%$ & \\
\hline
\end{tabular}

Fonte: elaboração dos autores com base em dados da ANS. 
A concentração em termos de receita também pode ser constatada na Tabela 7. As grandes operadoras, que têm mais de 100 mil beneficiários, responderam por $71 \%$ da receita e por $68 \%$ dos beneficiários. Já nas operadoras exclusivamente odontológicas, as grandes responderam por 72\% das receitas e por cerca de $77 \%$ dos beneficiários.

Tabela 7 - Receita e beneficiários de operadoras de planos de saúde, por porte das operadoras - 2012

\begin{tabular}{|l|c|r|r|r|}
\hline Porte da operadora & Receita $(\mathrm{R} \$)$ & $\%$ & Beneficiários* & \multicolumn{1}{c|}{$\%$} \\
\hline OPERADORAS MÉDICO-HOSPITALARES & 93.122 & 100 & 51.702 .320 & 100,0 \\
\hline Pequeno (até 20.000 beneficiários) & 7.059 & 8 & 4.058 .379 & 7,8 \\
\hline Médio (20.000 a 100.000 beneficiários) & 19.955 & 21 & 12.157 .117 & 23,5 \\
\hline Grande (acima de 100.000 beneficiários) & 66.109 & 71 & 35.486 .824 & 68,6 \\
\hline OPERADORAS EXCLUSIVAMENTE ODONTOLÓGICAS & 2.295 & 100 & 14.846 .920 & 100,0 \\
\hline Pequeno (até 20.000 beneficiários) & 272 & 12 & 1.506 .359 & 10,1 \\
\hline Médio (20.000 a 100.000 beneficiários) & 360 & 16 & 1.924 .187 & 13,0 \\
\hline Grande (acima de 100.000 beneficiários) & 1.663 & 72 & 11.416 .374 & 76,9 \\
\hline Total & 95.417 & & 66.549 .240 & \\
\hline
\end{tabular}

* Dados preliminares

Fonte: elaboração dos autores com base em dados da ANS.

O processo de concentração no setor de planos de saúde caracterizou-se pela mesma busca de economias de escala, observada no cenário internacional, juntamente com a necessidade de atender a regulamentação com a criação da ANS em 2000. Além disso, é válido ressaltar que esse movimento foi acompanhado por mudanças no sentido da verticalização das atividades. Se, nos anos 1980 e 1990, a verticalização foi marcada pela oferta dos hospitais dos seus próprios planos de saúde, mais recentemente as operadoras têm buscado ampliar o número de hospitais próprios. Além de reduzir custos com o atendimento direto aos beneficiários, em especial os custos com internações, a existência de rede própria também aumenta o poder de negociação com outros fornecedores.

A Amil, por exemplo, vinha, mesmo antes de ser adquirida pela UnitedHealth, realizando um processo intenso de compra, tanto de outras operadoras como de hospitais. Entre essas aquisições, podem ser destacadas a Blue Life em 2007, a Ampla e a Casa de Saúde Santa Lúcia em 2008, a Medial em 2009, a Saúde Excelsior em 2010, o Samaritano e a Pasteur do Rio de Janeiro em 2011. Em 2013, a Amil tinha em sua rede própria 22 hospitais e 50 clínicas médicas, além de mais dois hospitais em construção.

A entrada de operadores internacionais no mercado brasileiro pode acentuar ainda mais o movimento de consolidação do setor, assim como reforçar a estratégia de verticalização. Do ponto de vista da atração de investidores estrangeiros, o fato que mais chamou a atenção foi a entrada da americana UnitedHealth no Brasil ao comprar a Amil. O negócio foi fechado após um longo período de negociações. De acordo com informações da imprensa especializada, a venda de $90 \%$ do seu capital à UnitedHealth foi avaliada em R 9,8 bilhões. Além do valor da transação, a operação marcou 
a entrada da maior operadora de planos de saúde do mundo no mercado brasileiro. Como mostrado na terceira seção deste capítulo, em 2012 o faturamento da UnitedHealth atingiu cerca de US\$100 bilhões (enquanto o da Amil atingiu cerca de US\$ 5,1 bilhões).

De acordo com reportagem do jornal Valor Econômico, de 7 de agosto de 2013 (Koike, 2013a), após a aquisição pela UnitedHealth, a Amil negociava a compra de outros hospitais, com o objetivo não só de ampliar sua rede própria, consolidando a estratégia de verticalização, mas também de expandir sua abrangência em regiões onde a operadora ainda tem presença pequena.

Pode-se também registrar o interesse de outras empresas, como a Colsanitas, pertencente à holding colombiana Organizacion Sanitas Internacional (OSI). Em 2011, a Colsanitas comprou 45\% da operadora brasileira Universal Saúde e recentemente anunciou a intenção de aumentar a participação para 80\%. Segundo notícias veiculadas na imprensa, o objetivo do grupo no mercado brasileiro é comprar outras operadoras de planos de saúde e montar uma rede própria de hospitais e clínicas, nos moldes do que possui na Colômbia.

Boatos sobre a compra da Golden Cross pelo fundo norte-americano KKR também circularam na imprensa em 2012, embora efetivamente não tenha se concretizado nenhuma operação.

Em março de 2014, a terceira maior operadora de planos de saúde do Brasil teve uma das unidades do grupo adquirida por um grupo estrangeiro. O grupo NotreDame Intermédica vendeu a Intermédica para o fundo estadunidense de private equity Bain Company. Embora o valor oficial da operação não tenha sido revelado, a imprensa noticiou a cifra de US\$ 2 bilhões.

A participação de fundos de investimento no setor de saúde é outra novidade que tem contribuído para acelerar as transformações do setor de serviços de saúde privados no Brasil. Além da entrada da Bain Company adquirindo a Intermédica, podem ser citados vários outros exemplos de participação dos fundos de private equity no setor.

Um dos principais exemplos é a capitalização da empresa de medicina diagnóstica Hermes Pardini. Após a venda de 30\% de seu capital para o Gávea em 2011, a Hermes Pardini iniciou um processo de aquisições, em que se destaca a compra de $70 \%$ do capital da Diagnóstika, laboratório paulista especializado em exames de alta complexidade, com receita estimada de $\mathrm{R} \$ 27$ milhões. Além disso, anunciou a compra de $80 \%$ do Padrão, laboratório de Goiás com receita de R 50 milhões. Em 2012, fechou três aquisições: Digimagem (SP), Progenética (RJ) e o mineiro Biocod (Moura \& Koike, 2013).

Após intensa negociação envolvendo fundos de private equity nacionais e estrangeiros para a aquisição do controle do segundo maior laboratório do país, o Fleury. A Core Participações, formada pelos médicos que detêm o controle do Fleury, consolidou a venda de 13\% das ações para o fundo Advent. A disputa pelo Laboratório Fleury demonstra como os fundos financeiros vêm focando suas estratégias em aquisições de empresas de serviços de saúde em países em desenvolvimento.

O fundo Pátria, por sua vez, decidiu montar uma empresa no setor de exames de imagen, a Alliar, em 2011. Anteriormente, o Pátria tinha participação no grupo Dasa, porém desfez-se de sua participação em 2009. Entre 2013 e 2015, a Alliar realizou 11 aquisições de outros laboratórios de 
exames de imagem. As aquisições foram feitas em grande parte por meio da troca de ações das empresas adquiridas por ações da Alliar.

Na contramão dos movimentos anteriores, a Dasa registrou em 2014 o aumento da participação do empresário Edson Bueno e sua ex-mulher Dulce Pugliesi, antigos controladores da Amil. Com a aquisição de 48,35\% por R $\$ 2,3$ bilhões, a participação dos novos controladores saltou para 71,94\%. Fundos como Tarpon, Petros e Oppenheimar, tiveram, assim, sua participação diminuída no capital total do grupo (Koike, 2014).

No caso dos hospitais, o movimento de consolidação é relativamente mais lento em relação aos demais segmentos do setor de serviços. A existência de um grande número de hospitais sem fins lucrativos, aliada à restrição legal de participação de capital estrangeiro, tem reduzido os processos de fusão e aquisição. No entanto, cabe destacar que o maior grupo privado no setor, o Rede D'Or, tem adotado uma estratégia mais agressiva. De acordo com reportagem do jornal Valor Econômico, de 3 de abril de 2013 (Koike, 2013b), o grupo realizou 17 aquisições nos cinco anos anteriores, praticamente dobrando o faturamento entre 2010 e 2012 . Nesse processo, foi importante a parceria do BTG Pactual, que, além de ter participação minoritária, auxiliou o grupo hospitalar no lançamento de debêntures para financiar a expansão e também tem assessorado o grupo no processo de aquisições.

Essa intensa movimentação no setor de serviços de saúde pode também ser observada com a análise dos números referentes a fusões e aquisições no Brasil. ${ }^{3}$ No caso específico dos setores selecionados, as informações coletadas mostram uma tendência de aumento no número de operações, que vão atingir o volume máximo em 2008, com posterior redução no período pós-crise, porém mantendo um número de operações importantes. Em termos de valores, é possível verificar como estes atingem patamares mais elevados a partir de 2008, chegando ao valor máximo em 2012 (Gráfico 9).

\footnotetext{
${ }^{3}$ As informações sobre os processos de fusões e aquisições no Brasil foram coletadas na base de dados Zephir produzida pela empresa Bureau van Dijk (BvD).
} 
Gráfico 9 - Número e valor das operações de fusões e aquisições de empresas do setor de serviços de saúde no Brasil, em US\$ milhões - 2004-2013

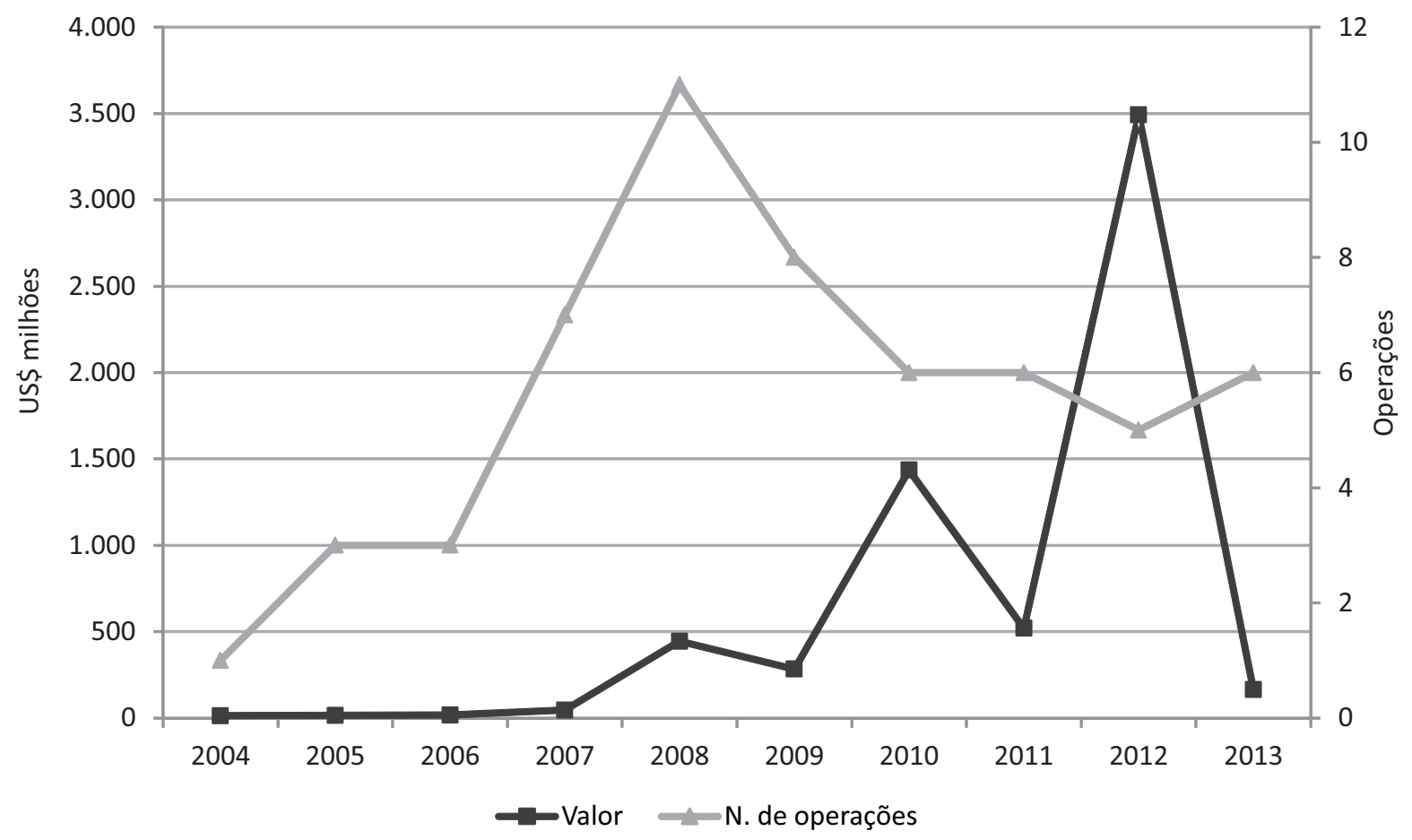

Fonte: elaboração dos autores com base em dados da Zephir-Bureau van Dijk (BvD).

Considerando o total de operações acumuladas entre 2004 e 2013, dos 58 registros encontrados, 23 não tinham registros de valor. A maior parte das operações se concentrou na faixa dos US\$ 10 a US\$ 50 milhões. Duas operações tiveram registro acima de US\$ 1 bilhão, e três na faixa entre US\$ 200 milhões e US\$ 1 bilhão (Tabela 8).

Tabela 8 - Operações de fusões e aquisições no Brasil no setor de serviços de saúde, por valor de operação - 2004-2013

\begin{tabular}{l|c|}
\hline Acima de US\$ 1 bilhão & 2 \\
\hline Entre US\$ 200 milhões e US\$ 1 bilhão & 3 \\
\hline Entre US\$ 50 e US\$ 200 milhões & 6 \\
\hline Entre US\$ 10 e US\$ 50 milhões & 15 \\
\hline Até US\$ 10 milhões & 9 \\
\hline Sem valor informado & 23 \\
\hline Total & 58 \\
\hline
\end{tabular}

Fonte: elaboração dos autores com base em dados da Zephir-Bureau van Dijk (BvD).

A grande maioria das operações ainda diz respeito a fusões e aquisições que envolvem empresas nacionais (Tabela 9). Porém, a participação de estrangeiros vem se tornando mais comum. Além 
disso, também vale destacar que, como mostra a entrada da UnitedHealth e da Bain Company em 2014 (ainda não captada na Tabela 9), em geral a entrada das estrangeiras acontece em grandes operações, que têm impactos relevantes sobre a estrutura do setor.

Tabela 9 - Operações de fusões e aquisições no Brasil no setor de serviços de saúde, por origem da adquirente, em US\$ milhões - 2004-2013

\begin{tabular}{|l|c|c|}
\hline \multicolumn{1}{|c|}{ Origem } & Operações & Valor \\
\hline Nacionais & 53 & $3.084,0$ \\
\hline Estrangeiros & 5 & $3.346,6$ \\
\hline França (2011) & 1 & n. d.* \\
\hline Estados Unidos (2012) & 1 & $3.207,9$ \\
\hline Canada (2012) & 1 & 120,7 \\
\hline Espanha (2013) & 1 & n. d. \\
\hline Colômbia (2013) & 1 & 18,0 \\
\hline Total & 58 & $6.430,6$ \\
\hline
\end{tabular}

*n. d. = não divulgado

Fonte: elaboração dos autores com base em dados da Zephir-Bureau van Dijk (BvD).

As operações captadas por empresa adquirente mostram uma concentração relativamente importante das aquisições entre as grandes empresas do setor. Interessante notar também que a comparação entre o número de operações registrado na base de dados e as informações colhidas na imprensa especializada permite intuir que as operações registradas pela Zephir-Bureau van Dijk (BvD) estão subestimadas, registrando apenas as maiores aquisições do setor. Por exemplo, a Rede D’Or aparece com apenas três operações na Tabela 10, enquanto outras fontes informam17 aquisições.

Tabela 10 - Operações de fusões e aquisições no Brasil no setor de serviços de saúde, por principais empresas - 2004-2013

\begin{tabular}{|l|c|c|}
\hline \multicolumn{1}{|c|}{ Adquirente } & Operações & Valor (US\$ milhões) \\
\hline Dasa & 13 & $1.218,9$ \\
\hline Fleury & 7 & 442,7 \\
\hline Amil/Amil participações & 4 & 501,6 \\
\hline Odontoprev & 4 & 38,8 \\
\hline Grupo Bradesco & 3 & 432,8 \\
\hline Rede D'Or & 3 & 163,4 \\
\hline Hermes Pardini & 3 & n. d* \\
\hline Sacmil & 3 & n.d \\
\hline Sul América & 3 & 33,6 \\
\hline Qualicorp & 2 & n. d \\
\hline
\end{tabular}

\footnotetext{
* n. d. = não divulgado.
}

Fonte: elaboração dos autores com base em dados da Zephir-Bureau van Dijk (BvD). 
Os dados analisados nesta seção, apesar das diferenças, finalizam um processo intenso de alterações na estrutura do setor de serviços de saúde. O movimento de consolidação no segmento de planos de saúde foi bastante intenso nos últimos anos, embora ainda exista um conjunto de operadores menores que podem ser alvo de novos movimentos no futuro. Também no setor de serviços de laboratório e diagnóstico, constata-se um acentuado processo de concentração. A capitalização por fundos de investimentos nacionais e internacionais tem sido um potente alavancador do movimento de consolidação.

O segmento menos sujeito ao processo, embora tenha passado também por um movimento de fusões e aquisições, é justamente o segmento hospitalar. Este setor tem se deparado, por um lado, com a busca por redução de custos e a estratégia de verticalização dos planos de saúde; por outro, tem enfrentado elevação de custos importantes, em especial no caso do avanço em tecnologias complexas, ${ }^{4}$ como forma de atingir segmentos de renda mais elevada. Essa situação tem levado vários hospitais menores a uma situação financeira delicada, o que afeta também o número de leitos colocados à disposição pelo setor privado.

Aparentemente, o movimento de consolidação em serviços de saúde ainda pode ter desdobramentos importantes no futuro, com implicações também importantes sobre as agências reguladoras e sobre os diversos níveis da política pública voltada para o setor.

\section{Mudanças Estruturais nos Serviços de Saúde}

Estas considerações finais têm o objetivo apenas de apontar de maneira preliminar algumas questões relativas às consequências do movimento descrito nas seções anteriores. Longe de ser um levantamento exaustivo, trata-se apenas de um primeiro esforço de análise, que deve necessariamente ser complementado através do diálogo com outros estudos sobre o setor.

Em primeiro lugar, cabe destacar o desafio colocado para as agências reguladoras. Em relação ao Conselho Administrativo de Defesa da Concorrência (Cade), os vários processos de concentração no setor têm sido objeto de crescente atenção da entidade, com a preocupação de reduzir o poder de mercado resultante das fusões e aquisições.

O desafio maior, no entanto, cabe à ANS. A busca por escala e melhores condições de custo e rentabilidade move o processo de concentração do setor, impulsionado inclusive por movimentos de capitalização advindos do processo de internacionalização de empresas e fundos financeiros em busca de novos espaços de valorização. Se, por um lado, esse movimento pode permitir investimentos em expansão e melhora de eficiência produtiva, por outro, pode acarretar práticas de elevação de preços, discriminação de preços, excluindo clientes de renda mais baixa do acesso a procedimentos mais sofisticados, racionalização excessiva, até mesmo em termos de mão de obra, reduzindo a qualidade do atendimento.

A inclusão de novos atores, como grandes grupos estrangeiros e fundos financeiros, reforça essa tensão, na medida em que aumenta o poder econômico dos agentes atuantes no setor e, ao mesmo

\footnotetext{
${ }^{4}$ O robô cirúrgico Da Vinci, por exemplo, tem custo estimado entre US\$ 1,5 e 3 milhões, somente da máquina, sem contar custos de treinamento e manutenção.
} 
tempo, induz a transferência de mecanismos de gestão que pressionam por maiores retornos e busca de eficiência operacional. $\mathrm{O}$ aumento do porte dos grupos privados com certeza exigirá maior capacidade de resposta da ANS, assim como será necessário que a agência consiga se antepor aos interesses puramente privados para poder gerar consequências positivas para a população atendida.

Do ponto de vista do controle dos hospitais, a aquisição das operadoras de planos de saúde por agentes estrangeiros cria uma situação de concorrência em que essa influência necessariamente será sentida. A concentração no setor de planos de saúde e a busca por redução de custos significam, sob a ótica dos hospitais, uma dificuldade para aumentar a receita. Essa pressão pode levar, por um lado, à replicação do movimento de consolidação no próprio setor de hospitais, como mostra a estratégia do grupo D'Or. Por outro, deve reforçar a necessidade de reduzir os custos sobre o restante da cadeia de fornecimento, fato que pode resultar em piora na qualidade, assim como em dificuldade de expandir o número de leitos. Em uma situação em que a pressão pelo aumento de leitos deve continuar aumentando, esse fator pode intensificar ainda mais a necessidade de investimentos públicos na expansão de sua rede de atendimento hospitalar.

Finalmente, cabe destacar que o movimento de internacionalização e concentração do setor privado de serviços de saúde também representa desafios para a articulação que está sendo organizada para o desenvolvimento do complexo industrial da saúde. Atores que atuam com uma lógica global tendem a reforçar laços com fornecedores globais de produtos, equipamentos, insumos e serviços tecnológicos, forçando um timing que pode ir de encontro ao esforço de construir capacidades produtivas e tecnológicas locais.

\section{Referências}

ARROW, K. J. Uncertainty and the welfare economics of medical care. The American Economic Review, 53(5): 941-970, 1963.

CHESNAIS, F. A Mundialização do Capital. São Paulo: Xama, 1996.

CONILL, E. M. Sistemas comparados de saúde. In: CAMPOS, G. W. S. et al. (Orgs.). Tratado de Saúde Coletiva. São Paulo, Rio de Janeiro: Hucitec, Editora Fiocruz, 2008.

IUNES, R. F. Demanda e demanda em saúde. In: PIOLA, S. F. \& VIANNA, S. M. (Orgs.). Economia da Saúde: conceitos e contribuição para a gestão da saúde. Brasília: Ipea, 1995.

JENSEN, M. Eclipse of the public corporation. Harvard Business Review, 67(5): 61-74, Sept-Oct. 1989.

KOIKE, B. Sob comando da UnitedHealth, Amil negocia compra de hospitais. Valor Econômico. São Paulo, 7 ago. 2013a. Disponível em: <www.valor.com.br/empresas/3224594/sob-comando-da-unitedhealth-amil-negociacompra-de-hospitais $>$.

KOIKE, B. Rede D’Or vai investir 500 milhões. Valor Econômico, São Paulo, 3 abr. 2013b. Disponível em: <http:// www.valor.com.br/empresas/3070998/rede-dor-vai-investir-r-500-milhoes>. Acesso em: março 2014.

KOIKE, B. Edson Bueno fica com 71,94\% da Dasa após investimento de R\$2,3 bi. Valor Econômico. São Paulo, 12 mar. 2014. Disponível em: <www.valor.com.br/empresas/3477080/edson-bueno-fica-com-7194-da-dasaapos-investimento-de-r-23-bi> . Acesso em: 15 mar. 2014.

MARKETLINE INDUSTRY PROFILE. Global Healthcare Providers. London: Marketline, 2013. 
MOURA, M \& KOIKE, B. Hermes Pardini fecha quinta aquisição e vai comprar mais. Valor Econômico. São Paulo, 24 jul. 2013. Disponível em: <www.valor.com.br/empresas/3208588/hermes-pardini-fecha-quinta-aquisicaoe-vai-comprar-mais>. Acesso em: março 2014.

PETERSON, J. New laws and rising costs create a surge of supersizing hospitals. The New York Times. New York, 12 ago. 2013.

SARTI, F. \& HIRATUKA, C. Indústria mundial: mudanças e tendências recentes. Texto para discussão IE-Unicamp, n. 186, 2010. Disponível em: <www.eco.unicamp.br/docdownload/publicacoes/textosdiscussao/texto186. pdf >. Acesso em: março 2014.

UNITED NATIONS CONFERENCE ON TRADE ANDE DEVELOPMENT (UNCTAD). World Investment Report 2004: the shift towards services. Geneva: UNCTAD, 2004. 